\title{
ERSTER ABSCHNITT: EINLEITUNG UND HISTORISCHE VORAUSSETZUNGEN
}

\author{
I. EINLEITUNG
}

\section{THEMA}

Auf dem Höhepunkt des Zweiten Weltkrieges, im Januar 1942, beendete Ernest Barker seine „Reflections on Government“, eine bemerkenswerte Studie über die historischen und ideellen Grundlagen der modernen Demokratie und deren Gegner. Nach einem Überblick über die sozialen und institutionellen Probleme des freiheitlichen Gemeinwesens im allgemeinen analysierte der in Cambridge lehrende Philosoph und Politikwissenschaftler leidenschaftslos und sachlich die zeitgenössischen „alternatives to democracy“, also das „system of the singleparty state“ in seinen drei Ausprägungen des sowjetrussischen Kommunismus, des italienischen Faschismus und des deutschen Nationalsozialismus ${ }^{1}$. Er bemühte dabei nicht den erhobenen Zeigefinger des britischen Demokraten, ja, er wies sogar darauf hin, daß auch bestimmte Abschnitte der Geschichte des eigenen Landes, etwa die Tudorzeit, von „totalitären Zügen“2 nicht frei gewesen seien, doch sein ablehnendes Urteil über jene drei - nur scheinbaren - Alternativen zur Demokratie fiel unmißverständlich aus: Denn alle drei - Kommunismus, Faschismus und Nationalsozialismus - bewegten sich außerhalb jenes in Jahrhunderten entstandenen "collective mind of Europe, engaged in maintaining and extending European standards of value“. Die fundamentale Tatsache aber, „that Europe has steadily constituted a single area of values“ 3 , könne durch das Wirken der totalitären Ideologien wohl zeitweilig verdunkelt, aber niemals vollkommen zunichte gemacht werden.

Im Bereich des Politischen findet diese einzigartige „area of values“ ihren Ausdruck vor allem - so wird man Barkers These weiterdenken dürfen - in dem Bemühen um die Konstituierung eines politischen Gemeinwesens, das einerseits Ordnung und Sicherbeit für jeden seiner Einwohner begründet, andererseits aber ebenfalls die Grundfreibeiten des Individuums garantiert und die (wenn auch in der Regel begrenzte) Mitwirkung des Bürgers an den fundamentalen politischen Entscheidungen innerhalb eben dieses Gemeinwesens sicherstellt, - das dessen inneren Zusammenhalt ermöglicht, doch andererseits die private Sphäre und die legitimen Interessen jedes einzelnen respektiert und schützt. In diesem Sinne hat man bereits früh die englische Verfassung, die sich

1 ERnest BARKER, Reflections on Government (1942), London u. a. 1967, S. 266ff.; vgl. Julia STAPLETON, Englishness and the Study of Politics. The social and political thought of Ernest Barker, Cambridge 1994, S. $203 \mathrm{ff}$.

2 Vgl. BARKER, Reflections on Government, S. 166.

3 Die Zitate ebd., S. 397. 
seit dem historischen Kompromiß der Glorious Revolution von 1688 in einem kontinuierlichen Prozeß ohne revolutionäre Umbrüche entwickelte, als einzigartig und beispielhaft zugleich angesehen. 1912 konnte Elie Halévy im Vorwort zu seiner „Englischen Geschichte im neunzehnten Jahrhundert“ die repräsentative Demokratie nicht nur als die große politische Erfindung des modernen England, sondern darüber hinaus als Teil des gemeinsamen Erbes der Menschheit bezeichnen ${ }^{4}$. Auch wer sich diesem etwas emphatischen Befund nicht anzuschließen vermag, wird zugeben müssen, daß jene zuerst in Westminster entwickelte Urform des parlamentarischen Regierungssystems eine historischpolitische Wirkungsgeschichte aufzuweisen hat, die in jeder Hinsicht einmalig und beeindruckend zugleich ist.

Die Tatsache, daß die englische Verfassung seit dem frühen 18. Jahrhundert, wie man treffend gesagt hat, „ein ebenso faszinierendes Vorbild war wie das römische Recht zur Zeit seiner Rezeption “5, ist keineswegs - wie später nicht selten kolportiert wurde - ausschließlich als Phänomen der liberal-bürgerlichen Opposition auf dem Kontinent (und ihrer durchsichtigen politischen Interessen) anzusehen ${ }^{6}$. Es ging um wesentlich mehr, nämlich um das Recht, genauer: die Herrschaft des Rechts. Albert Venn Dicey, einer der herausragenden Autoren der englischen Verfassungstheorie, hat über das Zeitalter „when the English constitution began to be criticised and admired by foreign thinkers“ bemerkt: „During the eighteenth century many of the continental governments were far from oppressive, but there was no continental country where men were secure from arbitrary power. The singularity of England was not so much the goodness or the leniency as the legality of the English system of government"

Im 19. Jahrhundert kamen weitere Aspekte hinzu, durch welche die Verfassung von England auf dem Kontinent, vor allem in Deutschland, zu einem vielbewunderten, auch durchaus kontrovers diskutierten, Vor- und Gegenbild

4 Elie Halévy, A History of the English People in the Nineteenth Century, Bd. I: England in 1815 (zuerst Paris 1913) London 1961, S. xiii: „Indeed, of all nations of Europe, it is perhaps the English whose institutions must, in many respects, be regarded as being beyond those of other nations, paradoxical, ,unique'.... The great political invention of modern England has been representative democracy. The invention, however, has spread and is still spreading, and with increasing rapidity, throughout Europe - indeed the entire world. Representative government in fact bids fair to become part of the common inheritance of mankind".

5 Julius Hatscheк, Allgemeines Staatsrecht auf rechtsvergleichender Grundlage, Bd.I, Leipzig 1909, S. 30.

6 In dieser Hinsicht ist typisch die Feststellung von EdUARD Fueter, Geschichte der neueren Historiographie, München u.a.1911, S.493: „Die Liberalen kanonisierten die englischen Institutionen. Ohne die eigentümlichen geographischen und wirtschaftlichen Verhältnisse Großbritanniens in Betracht zu ziehen, sahen sie in dem englischen Konstitutionalismus das Allheilmittel für alle politischen Schäden“.

7 Albert Venn Dicey, Introduction to the Study of the Law of the Constitution (Ndr. 8. Aufl., London 1915), Indianapolis 1982, S. 111. 
wurde ${ }^{8}$. Jetzt zählte nicht mehr nur die von Dicey durchaus mit Recht hervorgehobene Legalität, sondern vor allem Effizienz und Legitimität. Walter Bagehot entwickelte in seinem zuerst 1867 veröffentlichten Klassiker „The English Constitution" die verbindliche liberal-konservative Verfassungsinterpretation seiner Epoche, indem er zwischen den „leistungsfähigen“ und den „ehrwürdigen“ Teilen der Verfassung unterschied: Sicherten die „efficient parts“ des politischen Institutionengefüges (also Unterhaus und parlamentarische Regierung) dessen Bestand durch fortschreitende Veränderungs- und Anpassungsfähigkeit an neue Gegebenheiten und Erfordernisse, so gewährleisteten die „dignified parts“ der Verfassung (also Krone und Oberhaus) deren Legitimität, da sie die Ehrerbietung breiter Bevölkerungsteile gegenüber dem Gesamtgefüge der Institutionen weckten und bewahrten? .

Hierin also, in der gelungenen - und auch weiterhin gelingenden - Vermittlung von Altem und Neuem, schien die zeitgemäße Vorbildhaftigkeit jenes Systems zu liegen. Die kontinentalen Bewunderer und Kenner des scheinbar so einmalig funktionierenden britischen Regierungs- und Verwaltungssystems, von denen in Deutschland Rudolf Gneist hervorragte, hatten also allen Grund, sich mit der englischen Verfassung als einem zentralen Paradigma der zeitgenössischen politischen Moderne zu befassen ${ }^{10}$. Und wer, im Gegenzug, die englische Verfassung als Vorbild für die Erneuerung der politischen Institutionen auf dem Kontinent ausdrücklich ablehnte, war gehalten, dies ausführlich zu begründen. So konnte der junge Bismarck 1849 in der Zweiten Kammer des preußischen Parlaments seinen liberalen Gegnern zurufen: „Geben Sie uns alles Englische, was wir nicht haben, geben Sie uns englische Gottesfurcht und englische Achtung vor dem Gesetze, die gesammte englische Verfassung, aber auch die gesammten Verhältnisse des englischen Grundbesitzes, englischen Reich-

8 Vgl. hierzu u. a. Reinhard J. LAmer, Der englische Parlamentarismus in der deutschen politischen Theorie im Zeitalter Bismarcks (1857-1890). Ein Beitrag zur Vorgeschichte des deutschen Parlamentarismus, Lübeck u.a. 1963; HANs-Christof Kraus, Die deutsche Rezeption und Darstellung der englischen Verfassung im neunzehnten Jahrhundert, in: Aneignung und Abwehr. Interkultureller Transfer zwischen Großbritannien und Deutschland im 19. Jahrhundert, hrsg. v. Rudolf Muhs / Johannes Paulmann / WilliBALD STEINMETZ, Bodenheim 1998, S. 89-126.

9 Vgl. Walter Bagehot, The English Constitution, 4. Aufl., London 1885, S.4; er fügte hinzu: „There are two great objects which every constitution must attain to be successful, which every old and celebrated one must have wonderfully achieved: every constitution must first gain authority, and then use authority; it must first win the loyalty and confidence of mankind, and then employ that homage in the work of government" (ebd.).

10 Maßgebend hierfür waren in Deutschland die Arbeiten von GNEIST; siehe dazu u. a. RUDOLF GNEIST, Art. „Großbritannien, Verfassung“, in: Deutsches Staats-Wörterbuch. In Verbindung mit deutschen Gelehrten hrsg. v. Johann CASPAR Bluntschli / KaRL BRATER, Bd.IV, Stuttgart u.a. 1859, S. 423-460; DERS., Englische Verfassungsgeschichte, Berlin 1882; DERS., Das Englische Parlament in tausendjährigen Wandelungen vom 9. bis zum Ende des 19. Jahrhunderts, Berlin 1886. - Zum Zusammenhang vgl. auch ERICH J. HAHN, Rudolf von Gneist 1816-1895. Ein politischer Jurist in der Bismarckzeit, Frankfurt a. M. 1995, S. $57 \mathrm{ff}$. u. passim. 
thum und englischen Gemeinsinn, kurz und gut Alles, was wir nicht haben, dann will ich auch sagen, Sie können uns nach englischer Weise regieren "11. Und vier Jahre später beharrte er in einer internen Denkschrift für den späteren Kaiser Wilhelm I. darauf, daß England „für die continentalen Staaten ein irreleitendes Vorbild“ darstelle, da das Inselreich nicht nur durch seine geographische Lage in unvergleichlicher Weise gesichert sei, sondern auch über eine in seiner Art einzigartige, ökonomisch unabhängige und nur dem Gemeinwohl verpflichtete Gentry als Führungsschicht verfüge. Zudem habe, betonte er, „die neue Verfassung, seit der Reformbill, noch keine lange Probe bestanden, namentlich nicht in europäischen Kriegen von großem Maßstabe“12.

Mit den Jahren aber trübte sich das einstmals so vielbewunderte Bild der Tradition und Moderne auf unverwechselbare Weise vermittelnden - Verfassung Großbritanniens auf dem Kontinent ein. „Das englische Muster als allgemein anerkanntes, als wesentliches Bildungs- und Entwickelungsmittel für Deutschland besteht heute nicht mehr“, bemerkte Erich Marcks in einem im Jahre 1900 in London gehaltenen Vortrag ${ }^{13}$. Namentlich das neue deutsche Kaiserreich erschien jetzt als die effizienter organisierte und politisch moderner eingerichtete Macht, und nun wiederum waren es nicht wenige Engländer, die dem Bismarckreich Bewunderung entgegenbrachten ${ }^{14}$. Das Interesse, das ein-

11 OtTo von Bismarck, Die politischen Reden, hrsg. v. Horst KoHL, Bd.I, Stuttgart 1892, S. 125 (24.9.1849); er fügte freilich gleich hinzu: „Aber aus dieser Möglichkeit würde ich noch immer keine Verpflichtung für die preußische Krone entnehmen, sich in die machtlose Stellung drängen zu lassen, welche die englische Krone einnimmt, die mehr als ein zierlicher Kuppelschmuck des Staatsgebäudes erscheint, während ich in der unserigen den tragenden Mittelpfeiler desselben erkenne“ (ebd.); vgl. auch die weiteren Ausführungen ebd., S. 126.

12 Отто von Bismarck, Die gesammelten Werke, Friedrichsruher Ausgabe, Bd. I, Berlin 1924, S. 374 (Denkschrift an den Prinzen von Preußen, September 1853); weiter heißt es: „Außerdem bringt man bei Anpreisung der englischen Verfassung gewöhnlich nicht in Anschlag, daß England, ungeachtet aller erwähnten, bei uns nicht vorhandenen günstigen Vorbedingungen für constitutionelles Leben, in seiner glänzendsten Periode, zur Zeit der Pitt und Fox, mehr trotz der Verfassung, das heißt durch Bestechung und Gewalt, als in Einklang mit der Verfassung regirt wurde“ (ebd.).

13 ERICH MARCKs, Deutschland und England in den großen europäischen Krisen seit der Reformation (1900), in: DERS., Englands Machtpolitik. Vorträge und Studien, hrsg. v. WILLY ANDREAS, Stuttgart u. a. 1940, S.29-62, hier S.49, vgl. auch die weiteren Ausführungen ebd., S. $49 \mathrm{ff}$.

14 Vgl. dazu Günter Hollenberg, Englisches Interesse am Kaiserreich. Die Attraktivität Preußen-Deutschlands für konservative und liberale Kreise in Großbritannien 1860-1914, Wiesbaden 1974; zum Zusammenhang siehe auch PeTER PUlzer, Vorbild, Rivale, Unmensch. Das sich wandelnde Deutschlandbild in England 1815-1945, in: HANs SÜSSMUTH (Hrsg.), Deutschlandbilder in Dänemark und England, in Frankreich und in den Niederlanden, Baden-Baden 1996, S. 235-250; DERS., Der deutsche Michel in John Bulls Spiegel: Das britische Deutschlandbild im 19. Jahrhundert, in: Jahrbuch des Historischen Kollegs 1998, München 1999, S. 3-19; aufschlußreich ebenfalls: GÜNTHER BlAICHER, Konstanten in der englischen Wahrnehmung Deutschlands, in: Hans SüssmuTH (Hrsg.), Deutschlandbilder in Dänemark und England, in Frankreich und in den Niederlanden, Baden-Baden 1996, S. 251-266. 
zelne fleißige Forscher wie etwa Josef Redlich und Julius Hatschek in den deutschsprachigen Ländern den politischen und administrativen Institutionen Englands widmeten, drang über den Bereich akademischen Spezialistentums kaum noch hinaus. Die von den beiden Autoren in den Jahren kurz vor dem Ersten Weltkrieg veröffentlichten dickleibigen und grundgelehrten Werke zum britischen Staats-, Verwaltungs- und Parlamentsrecht sowie zur englischen Verfassungsgeschichte ${ }^{15}$ erfuhren nur noch einen Bruchteil derjenigen Aufmerksamkeit, die ihnen drei oder vier Jahrzehnte vorher gewiß gewesen wäre.

Die haßerfüllten Verzerrungen der Kriegspropaganda des Ersten Weltkrieges verdunkelten auf beiden Seiten das Bild ${ }^{16}$. Doch es bleibt - entgegen einem weit verbreiteten Vorurteil - festzuhalten, daß sich das deutsche Englandbild jener Zeit nicht nur in der Sombartschen Pseudokontrastierung deutscher „Helden“ und englischer „Händler“ erschöpfte ${ }^{17}$, sondern daß man sich in den beiden letzten Kriegsjahren - nicht zuletzt im Zusammenhang der Frage einer Verfassungsreform des Reiches - durchaus sachlich und weitgehend unpolemisch mit dem parlamentarischen Regierungssystem des Kriegsgegners auseinandergesetzt hat; die einschlägigen Schriften etwa von Hatschek, Tönnies, Schmoller und Hübner vermögen dies hinreichend $\mathrm{zu}$ belegen ${ }^{18}$. Doch nach dem Krieg war die Atmosphäre auf lange Zeit vergiftet; die Erfahrung des Versailler Vertrages verhinderte in Deutschland eine Wiederkehr der traditionellen liberalen Anglophilie. Die bedeutenden kultursoziologischen Englandstudien Herbert Schöfflers blieben in ihrer Rezeption weitgehend auf den akademischen Bereich beschränkt ${ }^{19}$. Und ein Werk wie „Der Geist der englischen Poli-

15 Josef Redlich, Englische Lokalverwaltung. Darstellung der inneren Entwicklung Englands in ihrer geschichtlichen Entwicklung und ihrer gegenwärtigen Gestalt, Leipzig 1901; DERS., Recht und Technik des Englischen Parlamentarismus. Die Geschäftsordnung des House of Commons in ihrer geschichtlichen Entwicklung und gegenwärtigen Gestalt, Leipzig 1905; Julius HATSCHEK, Englisches Staatsrecht mit Berücksichtigung der für Schottland und Irland geltenden Sonderheiten, Bd. I: Die Verfassung; Bd. II: Die Verwaltung, Tübingen 1905-1906; DERS., Englische Verfassungsgeschichte bis zum Regierungsantritt der Königin Victoria, München u.a. 1913; DERS., Das Staatsrecht des vereinigten Königreichs Grossbritannien-Irland, Tübingen 1914.

16 Zur deutschen antienglischen Kriegspublizistik vgl. statt vieler Rolf Peter Sieferle, Der deutsch-englische Gegensatz und die „Ideen von 1914“, in: Das kontinentale Europa und die britischen Inseln. Wahrnehmungsmuster und Wechselwirkungen seit der Antike, hrsg. v. GOTTFRIED NIEDHART, Mannheim 1993, S.139-160.

17 Werner Sombart, Händler und Helden - Patriotische Besinnungen, München u. a. 1915.

18 Julius Hatschek, Die Staatsauffassung der Engländer, Leipzig u. a. 1917; FerdinAND TÖNNIES, Der englische Staat und der deutsche Staat, Berlin 1917; Gustav Schmoller, Wäre der Parlamentarismus für Deutschland oder Preußen richtig? (1917), in: DERS., Zwanzig Jahre deutscher Politik (1897-1917). Aufsätze und Vorträge, München u. a. 1920, S. 183-189; RUDOLF HÜBNER, Die parlamentarische Regierungsweise Englands in Vergangenheit und Gegenwart, Tübingen 1918.

19 Siehe vor allem: HeRBERT SCHÖFfLER, England in der deutschen Bildung, Leipzig 1929; DERS., Vom Werden des englischen Parlamentarismus, Leipzig 1929; DERS., Die politische Schulung des englischen Volkes, Leipzig 1931. 
tik und das Gespenst der Einkreisung Deutschlands“ aus der Feder des Juristen Hermann Ulrich Kantorowicz blieb in seiner Art ein absolutes Unikum ${ }^{20}$.

In den dreißiger Jahren dominierten traditionelle Feindbilder vor verständigungsbereiter Annäherung, und nach dem Ausbruch des Zweiten Weltkrieges schien wiederum die Zeit gekommen für die großen, scheinbar unausweichlichen Dichotomien: Carl Schmitt kontrastierte staatliche Souveränität und freies Meer ${ }^{21}$, während Gerhard Ritter dem kontinentalen Machtstaat die angelsächsische Tendenz zur politischen Utopie gegenüberstellen zu können meinte 22 . Weniger bedeutende Autoren versuchten, England als hoffnungslos rückständige Vormacht einer geschichtlich überholten „bürgerlichen Welt“ bloßzustellen ${ }^{23}$ oder glaubten mit nicht geringem Aufwand an wissenschaftlichem Potential die Begriffs- und Gedankenwelt der „englischen Kulturideologie“ kritisch entlarven zu können ${ }^{24}$. Schlichteren Gemütern bot man das populäre Zerrbild vom „Raubstaat England“25. Daß auch nach Kriegsende, bis in die Gegenwart hinein, Karikaturen und Stereotypen - nunmehr wiederum überwiegend im angelsächsischen Bereich - wirksam waren und noch sind, hat die jüngste Vergangenheit gezeigt ${ }^{26}$.

Die Lehre von der englischen Verfassung als Königsweg zur Freiheit und von der singulären Qualität der britischen politischen Institutionen wurde allerdings auch in England selbst nachhaltig erschüttert: Herbert Butterfields Kritik an der „Whig interpretation of English history“ und vor allem die

20 Hermann Kantorowicz, Der Geist der englischen Politik und das Gespenst der Einkreisung Deutschlands, Berlin 1929.

21 CARL SChMiTT, Staatliche Souveränität und freies Meer. Über den Gegensatz von Land und See im Völkerrecht der Neuzeit (1941), in: DERS.: Staat - Großraum - Nomos. Arbeiten aus den Jahren 1916-1969, hrsg. v. GÜNTER Maschke, Berlin 1995, S. 401-422; zu Schmitts Englandbild siehe auch die Bemerkungen bei HANs-Christof Kraus, Anmerkungen zur Begriffs- und Thesenbildung bei Carl Schmitt, in: Politisches Denken. Jahrbuch 1998, Stuttgart u. a. 1998, S. 161-176, hier S. $168 \mathrm{ff}$.

22 Gerhard Ritter, Machtstaat und Utopie. Vom Streit um die Dämonie der Macht seit Machiavelli und Morus, 3./4. Aufl., München u.a. 1943; nach dem Krieg neu erschienen unter dem Titel: Die Dämonie der Macht. Betrachtungen über Geschichte und Wesen des Machtproblems im politischen Denken der Neuzeit, Stuttgart 1948.

23 Karl HeInZ PfefFer, England - Vormacht der bürgerlichen Welt, Hamburg 1942.

24 Carl August Weber (Hrsg.), Die englische Kulturideologie, Bde. I-II, Stuttgart u.a. 1941-1943.

25 So der Titel eines vom Propagandaministerium inspirierten, $1941 \mathrm{im}$ 301.-500. Tausend erschienenen Bilderalbums, hrsg. v. Cigaretten-Bilderdienst, Hamburg (mit einem entsprechenden Text von ERnSt Lewalter).

26 Siehe dazu u.a. GÜnther Heydemann, Partner oder Konkurrent? - Das britische Deutschlandbild während des Wiedervereinigungsprozesses 1989-1991, in: FrANZ BOSBACH (Hrsg.), Feindbilder - Die Darstellung des Gegners in der politischen Publizistik des Mittelalters und der Neuzeit, Köln u.a. 1992, S. 201-234, und Thomas Kielinger, Die Rolle des Stereotyps in der internationalen Politik - Das Beispiel der deutschbritischen Beziehungen, in: Staatsphilosophie und Rechtspolitik, hrsg. v. BURCKHARDT Ziemske / Theo Langheid / Heinrich Wilms / Görg Haverkate, München 1997, S. 1513-1528. 
Forschungen Lewis Namiers zur inneren Struktur der britischen Politik im 18. Jahrhundert verdunkelten in den dreißiger Jahren das einst so strahlende Bild $^{27}$. Der Zweite Weltkrieg und die unmittelbare Nachkriegszeit brachten wiederum eine positive Neubewertung der englischen Verfassung, die nicht nur dem Ansturm des Totalitarismus erfolgreich - wenn auch mit einigen kleinen Blessuren - widerstanden hatte, sondern sich jetzt auch wieder einmal als wandlungs- und reformfähig erwies ${ }^{28}$. Im Westen Deutschlands wurde - vermittelt durch einstige Emigranten wie etwa Karl Loewenstein, Gerhard Leibholz und Ernst Fraenkel, die während des Dritten Reiches in angelsächsischen Ländern Zuflucht gefunden hatten ${ }^{29}$, auch durch Übersetzungen wichtiger Standardwerke ${ }^{30}$ - das alte, im ganzen positive Bild des englischen Regierungsund Verfassungssystems erneuert. Auch die Erforschung des Parlamentarismus und seiner Geschichte setzte, wie sich versteht, zuerst am britischen Vorbild und Beispiel an ${ }^{31}$.

Dauerte auf der einen Seite die - maßvolle - Bewunderung für die englische Rechts- und Verfassungstradition, in der sich kontinuierlich die „Umwandlung

27 Herbert Butterfield, The Whig Interpretation of History (1931), Harmondsworth 1973; Lewis Namier, The Structure of Politics at the Accession of George III (1929), 2. Aufl., London u. a. 1968; DERS., England in the Age of the American Revolution (1930), 2. Aufl., London u. a. 1966. - Siehe dagegen noch, als charakteristisches Zeugnis für die Zeit unmittelbar nach dem Ersten Weltkrieg: H. A. SMITH, The Nature of our Constitutional Law, in: The Law Quarterly Review 36 (1920), S. 140-151. In den dreißiger Jahren wurde die immer noch durchaus einflußreiche ältere Position vertreten durch WILliam SEARLE HoldsworTh, A History of English Law, Bd.X, London 1938, bes. S. $713 \mathrm{ff}$. u. passim.

28 Siehe dazu etwa EDWARD JENKS, Das Staatsschiff. Grundgedanken zur Staatswissenschaft (engl. 1939), Kempen 1947, bes. S.79ff., 86ff.; William Ivor Jennings, Die britische Verfassung, Paderborn 1946; DERs., The Law and the Constitution, London 1948; G. M. Young, Government, in: The Character of England, hrsg. v. ERNEST BARKER, Oxford 1947, S. 85-111; William Allen Viscount JowitT of Stevenage, The Bristish Constitution, in: Our Way of Life. Twelve Aspects of the British Heritage, London 1951, S.21-32; ERNEST BARKeR, British Constitutional Monarchy, in: DERS.: Essays on Government, 2. Aufl., Oxford 1951, S. 1-22. - Besonders charakteristisch auch die Einleitung zum Hauptwerk des Historikers ARTHUR Bryant, The Story of England. Makers of the Realm, London 1953, S. 11-25 („Prelude: The Islanders“).

29 Karl Loewenstein, Der britische Parlamentarismus. Entstehung und Gestalt, Reinbek bei Hamburg 1964; DERS., Staatsrecht und Staatspraxis von Großbritannien, Bde. I-II, Berlin u. a. 1967; Gerhard LeIBHOlz, Staat und Gesellschaft in England, in: DERS.: Strukturprobleme der modernen Demokratie, 3. Aufl., Karlsruhe 1967, S.206-221; ERNST FrAENKel, Historische Vorbelastungen des deutschen Parlamentarismus, in: DERS., Deutschland und die westlichen Demokratien, 5. erw. Aufl., Stuttgart u. a. 1973, S. 13-31.

30 Sir Ivor W. Jennings, Das britische Regierungssystem, dt. v. Gerhard A. Ritter, Köln u. a. 1958.

31 Grundlegend waren und sind in der deutschen Forschung die Arbeiten von KURT KLUXEN, Das Problem der politischen Opposition. Entwicklung und Wesen der englischen Zweiparteienpolitik im 18. Jahrhundert, Freiburg u.a. 1956; DERS., Die geistesgeschichtlichen Grundlagen des englischen Parlamentarismus, in: Parlamentarismus, hrsg. v. KURT Kluxen, 5. Aufl., Königstein/Ts. 1980, S. 99-111; DERS., Geschichte und Problematik des Parlamentarismus, Frankfurt a. M. 1983. 
von Geschichte in Gesetz" vollzog und das Recht - nach einer Formulierung Ciceros - „als gespeicherte Erfahrungsweisheit“ verstanden wurde ${ }^{32}$, weiterhin an, so machten sich doch etwa drei Jahrzehnte nach Kriegsende in Großbritannien immer stärkere „Verfassungszweifel“ bemerkbar, die zu einer gegenwärtig noch nicht abgeschlossenen Debatte über Gegenwart und Zukunft der alten ungeschriebenen Verfassung geführt haben ${ }^{33}$. Dabei geht es nicht nur um die Zukunft der Monarchie, sondern in erster Linie um die Frage einer Anpassungsmöglichkeit der alten britischen Parlamentssouveränität an die politischen Erfordernisse der europäischen Einigung ${ }^{34}$, die von einigen Autoren unter Berufung auf die alte Rechtsordnung und Verfassungstradition vehement bestritten wird ${ }^{35}$. Schließlich taucht auch immer wieder die Forderung nach einer Verfassungsurkunde für Großbritannien auf; neue Verfassungsentwürfe werden zuweilen gleich mitgeliefert ${ }^{36}$. Neuerdings ist sogar die Frage aufge-

32 Siehe Sir Ivor JenNings, Die Umwandlung von Geschichte in Gesetz, Köln u.a. 1965; Martin Kriele, Recht als gespeicherte Erfahrungsweisheit - $\mathrm{Zu}$ einem Argument Ciceros, in: DERS.: Die demokratische Weltrevolution und andere Beiträge, Berlin 1997, S. 383-393, bes. S. $386 \mathrm{ff}$.

33 Einen ersten skizzenhaften Überblick lieferte 1984 Werner vON Simson, Verfassungszweifel in England, in: Einigkeit und Recht und Freiheit. Festschrift für Karl Carstens zum 70. Geburtstag, hrsg. v. BODO BÖRner / HeRMANN JAHrReiss / Klaus STERn, Bd. II, Köln u. a. 1984, S. 853-865; vgl. schon die frühere Abhandlung: WeRNER VON SIMSON, Das Common Law als Verfassungsrecht, in: DERS., Der Staat und die Staatengemeinschaft. Öffentlichrechtliche Abhandlungen, Baden-Baden 1978, S. 89-105.

34 Siehe statt vieler etwa Peter Bromhead, Britain's developing Constitution, London 1974; Vernon Bogdanor, Present Problems of the British Constitution, in: Deutscher und Britischer Parlamentarismus, hrsg. v. Adolf M. Birke / Kurt Kluxen, München u.a. 1985, S. 117-134; sowie die Beiträge in dem Sammelband von ROBERT BLACKBURN, (Hrsg.), Constitutional Studies. Contemporary Issues and Controversies, London 1992, darin besonders den Aufsatz des Hrsgs., The Future of the British Monarchy, in: ebd., S.1-13.

35 Vgl. als charakteristisches Beispiel etwa Roger SCRUTON, The Abolition of Thought, in: The Salisbury Review 15 (1996) H. 1, S. 20: „We have not gone through the two centuries of revolution, war, occupation and defeat that have characterised all the other countries in the Union [gemeint ist die Europäische Union, H.-C.K.]. We have not gone through this because we have had an independent legal system, based on the common law, and outside of the control of the state. Through that legal system our national sovereignty has grown up as a property of the British people and not of Parliament. It is a sovereignty vested in the common law and also in the Crown as representative of that law. This means that we have always enjoyed a freedom and a stability which have been the exception and not the rule on the continent. It is perfectly reasonable for us to object to being brought under a system of law which not only dictates to us but is derived from the Napoleonic jurisdiction against which half of Europe once spent fifty years in rebellion. It is perfectly reasonable to say not only that there has been a loss of sovereignty, but that it will be a disaster for this country, whose political and national character is founded in an assumption of sovereignty of a very peculiar kind“.

36 Vgl. u. a. den Hinweis bei Michael MaURER, Kleine Geschichte Englands, Stuttgart 1997, S. 472; sodann Geraint Parry, Finer's Sixth Constitution: The Continuing Debate on a Written Document for Britain, in: Government and Opposition 29 (1994), S. 652-675; ein ausführlicher, von englischen Politologen ausgearbeiteter Entwurf (inklusive eingehender Kommentierung) findet sich in: Institute for Public Policy Research (Hrsg.), A Written Constitution for the United Kingdom, London u. a. 1993. 
worfen worden, ob Großbritannien überhaupt noch über eine „Verfassung“ im vollen Sinne dieses Begriffs verfüge ${ }^{37}$. Ob die gegenwärtig - um die Wende vom 20. zum 21. Jahrhundert - sich vollziehende Reform des Oberhauses weitere Verfassungsreformen mit sich bringen wird, ist noch nicht abzusehen, doch manches deutet darauf hin, daß die traditionelle Flexibilität der englischen politischen Ordnung auch künftige Veränderungen bewältigen und verkraften wird ${ }^{38}$.

Es zeigt sich, erstaunlich genug, daß bei näherem Hinsehen die heute geführte Diskussion sehr alt ist; manche der erörterten Probleme und der dabei verwendeten Argumente sind tatsächlich bereits vor zweihundert bis dreihundert Jahren zur Sprache gekommen. Das Thema dieser Untersuchung ist also aktueller, als man auf den ersten Blick vermuten mag; es handelt sich gewissermaßen um die Rekonstruktion und Analyse der ersten Etappe eines Denk- und Diskussionsprozesses, der bis in die Gegenwart hinein anhält. Die von Ernest Barker in finsterer Zeit namhaft gemachten und gerechtfertigten „European standards of value "39, die sich im Bereich des Politischen in der allgemeinen Bemühung um die Schaffung eines zugleich Ordnung, Sicherheit, Freiheit und Recht sichernden Gemeinwesens ausdrückten, haben in der frühen Debatte um Bedeutung und Grenzen des englischen Verfassungsparadigmas einen Niederschlag gefunden, dem nachzuspüren sich lohnt ${ }^{40}$. Und dies deshalb, weil in eben dieser Debatte fast alle zentralen Themen des neueren europäischen politischen Denkens zur Sprache gekommen sind. Die Geschichtlichkeit unserer nur scheinbar so unhistorischen „postmodernen“ Gegenwart läßt sich kaum treffender anschaulich machen als am Ausweis eines gemeineuropäischen politischen Diskurses vor mehr als zwei Jahrhunderten, dessen wichtigste Elemente noch heute aktuell sind.

Dieser politische Diskurs begann vor etwas mehr als dreihundert Jahren, nach dem Ende der Glorious Revolution von 1688/89, er verstärkte sich seit der Mitte des 18. Jahrhunderts mit dem Erscheinen von Montesquieus „De l'esprit des lois“ und erreichte einen weiteren Höhepunkt in den Jahren vor dem Ausbruch der Französischen Revolution. Der erste Abschnitt jener großen gemeineuropäischen Debatte über die englische Verfassung - allerdings unter besonderer Berücksichtigung der Rezeption im deutschsprachigen Bereich - ist das Thema der vorliegenden Studie ${ }^{41}$. Sie besteht dementsprechend aus zwei

7 Anthony King, Does the United Kingdom still have a constitution?, London 2001.

38 So auch Walter LeISNER, Großbritannien (Verfassung, Verfassungsgeschichte) Commonwealth, in: DERS.: Staat. Schriften zu Staatslehre und Staatsrecht 1957-1991, hrsg. v. JosEF ISENSEE, Berlin 1994, S. 179-188, hier S. 185.

39 Siehe oben, Anm. 3.

40 Auf die Bedeutung dieser Dichotomie (hier als Autorität und Freiheit bezeichnet) verweist ebenfalls JÜRGEN KLeIn, Die Genesis Englands zur Moderne als Fragestellung eines literatur- und intellektualgeschichtlichen Forschungsprogramms, in: Archiv für Kulturgeschichte 64 (1982), S.371-401, hier S. 391, 393.

41 Beabsichtigt war vom Verfasser ursprünglich eine im wesentlichen auf Deutschland beschränkte rezeptionsgeschichtliche Untersuchung für die Jahre 1750 bis 1832. Doch es 
Teilen: im ersten wird, nach einem zusammenfassenden Überblick über die englische Verfassungsgeschichte dieser Ära, das Bild der Verfassung von England rekonstruiert, wie es sich anhand ausgewählter Beispiele in der historisch-politischen und juristischen Literatur Englands, Frankreichs, der frankophonen Schweiz und Italiens darstellt ${ }^{42}$. Und im zweiten wird die - vielfach nicht nur an englische, sondern besonders an französische Quellen anknüpfende - deutsche Debatte im genannten Zeitraum nachgezeichnet und untersucht.

\section{FORSCHUNGSSTAND}

Eine Gesamtdarstellung der Rezeption und Diskussion des englischen Verfassungsmodells im Ancien Régime liegt bisher nur für den französischen bzw. frankophonen Sprach- und Kulturbereich vor: in zwei Studien, die Gabriel Bonno 1931 und 1948 publiziert hat ${ }^{43}$. Sie enthalten (ohne vollständig zu sein) viel Material, bieten jedoch wenig Analyse, und ein vergleichender Blick auf England wird kaum, auf Deutschland gar nicht geworfen. Die Zeit des frühen 18. Jahrhunderts findet sich aufgearbeitet in einer älteren, überaus reichhaltigen und nach wie vor grundlegenden Studie von Joseph Dedieu, während die Jahrzehnte zwischen dem Ende des Siebenjährigen Krieges und dem Ausbruch der Französischen Revolution in einer ebenfalls noch nicht überholten amerikanischen Untersuchung von Frances Acomb aus dem Jahre 1950 behandelt worden sind ${ }^{44}$. Der Brite Kingsley Martin hat in seiner zuerst 1929 erschienenen Arbeit über das liberale politische Denken im Frankreich der Aufklärung auch der Diskussion um die englische Verfassung einen eigenen Abschnitt

stellte sich bald heraus, daß Montesquieus Verfassungsinterpretation, die den Ausgangspunkt der Arbeit bilden sollte, ihrerseits wiederum in einer seit dem späten 17. Jahrhundert sich herausbildenden Tradition stand, die ausführlich berücksichtigt werden mußte, um das deutsche Interesse an der englischen Verfassung zu verstehen. Auch die für die Zeit vor 1750 vorhandenen deutschen (und außerdeutschen) Quellen erwiesen sich, entgegen ersten Vermutungen, als ebenso interessant wie ausgesprochen ergiebig. Um den Umfang der Studie angesichts der überwältigenden Fülle des Materials nicht ausufern zu lassen, wurde eine Zweiteilung notwendig: Die vorliegende Arbeit behandelt die Zeit bis zum Ende des Ancien Régime; eine spätere zweite Studie soll die folgende Epoche bis zum Ende des 19. Jahrhunderts in den Blick nehmen.

42 Aus dem italienischen Schrifttum wurde nur ein - allerdings zentraler, weil in ganz Europa rezipierter - Autor herangezogen: Gaetano Filangieri.

43 GABRIEl BonNo, La constitution britannique devant l'opinion francaise de Montesquieu a Bonaparte, Paris 1931, Ndr. Genf 1970; DERS., La culture et la civilisation britanniques devant l'opinion française de la paix d'Utrecht aux Lettres philosophiques (1713-1734), Philadelphia 1948, bes. S. 37 ff. u. passim.

44 Joseph Dedieu, Montesquieu et la tradition politique anglaise en France. Les sources anglaises de l' „Esprit des lois“, Paris 1909; Frances ACOMB, Anglophobia in France 1763-1789. An Essay in the History of Constitutionalism and Nationalism, Durham/N. C. 1950. 
gewidmet ${ }^{45}$. Und natürlich ist das Thema auch in vielen Einzelstudien zu herausragenden Autoren - besonders zu Montesquieu und Voltaire - zur Sprache gebracht worden ${ }^{46}$.

Eine Geschichte der englischen Verfassungstheorie des 18. Jahrhunderts existiert dagegen nicht - wohl aber eine Fülle von Darstellungen über das politische und juristische, auch das ökonomische Denken britischer Autoren im Ancien Régime, in denen mehr oder weniger auf das Thema eingegangen wird. Nach der brillanten, immer noch klassischen Darstellung des englischen Denkens im Aufklärungszeitalter durch Leslie Stephen ${ }^{47}$ haben in der ersten Hälfte des 20. Jahrhunderts weitere prominente Autoren wie etwa Cecil S. Emden, Harold J. Laski oder William I. Jennings in ihren einschlägigen Arbeiten auch über einzelne Aspekte der Verfassungstheorie des 18.Jahrhunderts gehandelt ${ }^{48}$. Ende der 1930er Jahre kamen Sir William S. Holdsworth mit den das 18. Jahrhundert behandelnden Bänden seiner Englischen Rechtsgeschichte sowie Frank T. H. Fletcher mit einer wichtigen Arbeit zur englischen Rezeption Montesquieus hinzu ${ }^{49}$.

Nach dem Zweiten Weltkrieg erschien eine Reihe von Darstellungen, in denen das Thema in unterschiedlichen Perspektiven und Zusammenhängen auftaucht. Stellvertretend für manche anderen Publikationen sei hier nur hingewiesen auf Corinne C. Westons Untersuchung über das House of Lords im älteren englischen Verfassungsdenken und auf Maurice J. C. Viles Studie über Gewaltenteilung und Verfassungstheorie ${ }^{50}$. Aus den letzten beiden Jahrzehnten ragen John A. W. Gunns Arbeit „Beyond Liberty and Property“, sodann das Hauptwerk der „revisionistischen“ Schule zum 18. Jahrhundert, Jonathan C. D. Clarks „English Society 1686-1832“, sowie die rechtshistorische Studie „The Province of Legislation Determined“ von David Lieberman hervor ${ }^{51}$. Doch

45 Kingsley Martin, French Liberal Thought in the Eighteenth Century. A Study of Political Ideas from Bayle to Condorcet, hrsg. v. J. P. MAYER (zuerst 1929), New York 1963, S. 147-169.

46 Siehe dazu unten, Kap. III-IV.

47 Leslie Stephen, History of English Thought in the Eighteenth Century, Bde. I-II, London 1881.

48 Cecil S. Emden, The People and the Constitution. Being a History of the Development of the People's Influence in British Government, 2. Aufl., Oxford 1956; HAROLD J. LASKI, Political Thought in England from Locke to Bentham, London 1932; SIR William IvOR Jennings, The Law and the Constitution (1933), London 1948.

49 Holdsworth, A History of English Law, Bde.X-XII, bes. Bd.X, S.713ff., Bd.XII, S. 332 ff., 702 ff.; F. T. H. FleTCHeR, Montesquieu and English Politics (1750-1800), London 1939, Ndr. Philadelphia 1980.

50 Corinne Comstock Weston, English Constitutional Theory and the House of Lords 1556-1832, New York u.a. 1965; Maurice John Crawley Vile, Constitutionalism and the Separation of Powers, Oxford 1967.

51 J. A. W. GunN, Beyond Liberty and Property. The Process of Self-Recognition in Eighteenth-Century Political Thought, Kingston u. a. 1983; Jonathan C. D. Clark, English Society 1688-1832. Ideology, social structure and political practice during the ancien regime, Cambridge 1988; DAVID Lieberman, The province of legislation determined. Legal theory in eighteenth-century Britain, Cambridge 1989. 
auch diese Autoren liefern nur Bruchstücke, bestenfalls einzelne Bausteine zur noch ungeschriebenen Geschichte des englischen Verfassungsdenkens im 18. Jahrhundert, ebenso wie einzelne Spezialstudien zu zentralen Autoren, etwa zu Bolingbroke oder Blackstone ${ }^{52}$.

Das Thema der englischen Verfassung in der Rezeption durch das politische Denken der Deutschen im 18. und im 19. Jahrhundert ist seit Beginn des zwanzigsten Jahrhunderts verschiedentlich untersucht worden - zumeist jedoch im Rahmen thematisch und inhaltlich stark eingegrenzter Fragestellungen und nicht selten auch auf der Grundlage eines (jedenfalls aus heutiger Sicht) allzu beschränkten Quellenmaterials. Daß dabei nicht zuletzt ebenfalls politisch-ideologische Elemente und zeithistorische Faktoren mit hineinspielten und die Perspektive der jeweiligen Autoren oft wesentlich prägten, versteht sich von selbst.

Auf die Bedeutung des Themas wies zuerst Georg Kaufmann in einem im Jahre 1900 gehaltenen und kurz darauf publizierten Vortrag hin, der bereits wesentliche Etappen der deutschen Rezeptionsgeschichte ebenso knapp wie gut informiert nachzeichnete ${ }^{53}$. Ihm folgte 1903 der welfisch gesinnte Heinrich Langwerth von Simmern, der in einer eher allgemein gehaltenen, kritischfreundschaftlichen Schrift die frühere deutsche Anglophilie bis zu einem gewissen Grade zu rehabilitieren versuchte ${ }^{54}$. Noch während des Ersten Weltkrieges und in den frühen Nachkriegsjahren erschienen wissenschaftliche Untersuchungen zur Geschichte der deutschen politischen Bildungsreisen im späten 18. und frühen 19. Jahrhundert, zur deutschen Rezeption Edmund Burkes sowie zur Entwicklung des deutschen Englandbildes im allgemeinen von Robert Elsasser, Frieda Braune und Franz Muncker, die ihren Wert - wenn auch in mancher Hinsicht nur noch als Materialsammlung - bis heute behalten haben und als Ausgangspunkt einer Neubearbeitung des Themas Beachtung finden müssen ${ }^{55}$.

Um 1930 erschien eine Reihe weiterer Arbeiten, zumeist geschichtswissenschaftliche Dissertationen, in denen die deutsche Rezeption nun eingehender und auf etwas breiterer Quellengrundlage untersucht wurde. Widmeten sich Theodor Wilhelm und Friedrich Klenk in ihren kenntnisreichen Studien dem Einfluß des englischen Verfassungsbildes auf das liberale und konservative deutsche Denken in der ersten Hälfte des 19. Jahrhunderts (allerdings mit eini-

52 Siehe dazu unten, Kap. III-IV.

53 Georg Kaufmann, Die englische Verfassung in Deutschland, in: Hansische Geschichtsblätter 28 (1900), S. 1-22.

54 Heinrich Freiherr Langwerth von Simmern, Deutschtum und Anglophobie. Zur Beurteilung Englands, Wiesbaden 1903, S. $98 \mathrm{ff}$.

55 RoBert Elsasser, Über die politischen Bildungsreisen der Deutschen nach England, Heidelberg 1917; Frieda Braune, Edmund Burke in Deutschland. Ein Beitrag zur Geschichte des historisch-politischen Denkens, Heidelberg 1917; FrAnZ MunCKER, Anschauungen vom englischen Staat und Volk in der deutschen Literatur der letzten vier Jahrhunderte, Bde. I-II, München 1918, 1925. 
gen Rückblicken auf das 18.$)^{56}$, so bearbeiteten die - offenbar unabhängig voneinander entstandenen - knappen Dissertationen des Brandenburg-Schülers Erich Witte in Leipzig und der Ritter-Schülerin Annelise Mayer in Freiburg vornehmlich das 18. Jahrhundert; die letztere allerdings mit einem Ausblick bis 1830 und einer (unverkennbar den aktuellen Forschungsinteressen des akademischen Lehrers zuarbeitenden) schwerpunktmäßigen Behandlung der Auffassungen des Freiherrn vom Stein ${ }^{57}$. Weitgehend außerhalb der wissenschaftlichen wie der politischen Diskussion dieser Jahre stand das bereits erwähnte im Zusammenhang des aufgeheizten Zeitklimas durchaus mutige - Buch von Hermann Kantorowicz, der darin auch die Ursprünge und Wege deutscher Anglophilie und Anglophobie knapp nachzeichnete ${ }^{58}$.

Ende der dreißiger und Anfang der vierziger Jahre legte der Greifswalder Historiker Hermann Christern zwei Arbeiten zum Thema von unterschiedlichem Wert vor. Mit seiner 1939 unter dem Titel „Deutscher Ständestaat und englischer Parlamentarismus am Ende des 18. Jahrhunderts“ erschienenen Monographie scheint er (mit z. T. durchaus brauchbaren Einzelanalysen zu Schlözer, Spittler, Rehberg und Brandes) zuerst versucht zu haben, eine deutsch-englische Gemeinsamkeit im Zeichen des - gegen den westlich-französischen Rationalismus und die „Ideen von 1789“ gerichteten - „germanisch-organischen“ Staatswesens zu beschwören, während er in den Schlußpassagen des Buches wiederum zur Feststellung eines tiefen Gegensatzes zwischen britischem „Individualismus“ und deutscher „Volksgemeinschaft" gelangen zu können meinte ${ }^{59}$. Sein 1943 postum erschienener Beitrag zu dem Sammelwerk „Die englische Kulturideologie" allerdings erhob sich nicht mehr wesentlich über das Niveau vergleichbarer Kriegspropaganda in pseudoakademischem Gewande 60 .

Nach dem Zweiten Weltkrieg war es neben und nach Fritz Valjavec ${ }^{61}$ zuerst Franz Uhle-Wettler, der das Thema der deutschen Englandrezeption in seiner bedeutenden, den Durchschnitt akademischer Arbeiten in dieser Zeit deutlich

56 Theodor Wilhelm, Die englische Verfassung und der vormärzliche deutsche Liberalismus. Eine Darstellung und Kritik des Verfassungsbildes der liberalen Führer, Stuttgart 1928; Friedrich KlenK, Die Beurteilung der englischen Verfassung in Deutschland von Hegel bis Stahl, phil. Diss. Tübingen 1930.

57 ERICH WITTE, Die englische Staatsverfassung im Urteil der Deutschen des achtzehnten Jahrhunderts, phil. Diss. Leipzig 1929; ANNELISE MAYER, England als politisches Vorbild und sein Einfluß auf die politische Entwicklung in Deutschland bis 1830, phil. Diss. Freiburg i. Br. 1931.

$58 \mathrm{Vgl}$. Kantorowicz, Der Geist der englischen Politik, S. $22 \mathrm{ff}$.

59 Vgl. Hermann Christern, Deutscher Ständestaat und englischer Parlamentarismus am Ende des 18. Jahrhunderts, München 1939, bes. S. $231 \mathrm{ff}$. u. passim.

60 Hermann Christern, Einfluß und Abwehr englischer politischer Ideologie in Deutschland vom 18. bis ins 20.Jahrhundert, in: Die englische Kulturideologie, Bd.II, hrsg. v. Carl August Weber, Stuttgart u. a. 1943, S. 283-396.

61 Vgl. die noch während des Krieges erarbeitete, zuerst 1951 publizierte klassische Darstellung: Fritz Valjavec, Die Entstehung der politischen Strömungen in Deutschland 1770-1815, Kronberg/Ts. u.a. 1978, hier S.244-254; Hinweise auf die Bedeutung des 
überragenden (doch leider ungedruckt gebliebenen) Dissertation über „Staatsdenken und Englandverehrung bei den frühen Göttinger Historikern“ aufnahm und in ebenso tiefdringenden wie präzisen Einzelanalysen zu Achenwall, Schlözer, Spittler, Brandes, Rehberg und Heeren vertiefte. Der Autor betonte die Traditionsorientierung dieser Autoren und warnte vor einer vorschnellen Zuordnung zum Frühliberalismus ${ }^{62}$, während F. Gunther Eyck in einem 1957 publizierten Aufsatz gerade den Einflüssen britischer parlamentarischer Theorie und Praxis auf die konstitutionellen Ideen der frühen deutschen Liberalen nachspürte63. Richard Lamers und Charles E. McClellands 1963 bzw. 1971 erschienene, gründliche Monographien zur politischen und historiographischen Englandrezeption waren fast ausschließlich dem 19. Jahrhundert gewidmet ${ }^{64}$, und dies trifft auch auf einzelne - teils mehr, teils weniger ergiebige - Aufsätze zu, die zwischen 1971 und 1981 von Karl W. Hardach, Günter Hollenberg und Wolfgang J. Mommsen vorgelegt wurden ${ }^{65}$; beachtenswerte Detailstudien zu Bayern und Österreich publizierten Leonhard Lenk und Wilhelm Brauneder ${ }^{66}$.

Um die Mitte der achtziger Jahre erschienen zwei umfangreiche Arbeiten mit inhaltlich ähnlicher Zielsetzung: Während Sisko Haikala 1985 in ihrer in Finnland publizierten Dissertation das deutsche Englandbild des späten 18. Jahrhunderts unter dem Stichwort der „englischen Freiheit“ auf breiter Quel-

Themas ebenfalls schon bei Wolfgang STAMmLer, Politische Schlagworte in der Zeit der Aufklärung, in: Lebenskräfte der abendländischen Geistesgeschichte, hrsg. v. WOLFGANG STAMMLER, Marburg 1948, S. 199-259, bes. S. 208 f.

62 Vgl. Franz Uhle-WeTtLer, Staatsdenken und Englandverehrung bei den frühen Göttinger Historikern, phil. Diss. (masch.) Marburg 1956, bes. S. $236 \mathrm{ff}$.

63 F. GUNTHER EYCK, English and French Influences in German Liberalism before 1848, in: Journal of the History of Ideas 18 (1957), S.313-341.

64 Lamer, Der englische Parlamentarismus in der deutschen politischen Theorie; CHARLeS E. McClelland, The German Historians and England. A Study in Nineteenth-century Views, Cambridge 1971.

65 KARL W. HARDACH, Anglomanie und Anglophobie während der Industriellen Revolution in Deutschland, in: Schmollers Jahrbuch für Wirtschafts- und Sozialwissenschaften 91 (1971), S. 153-181; GÜNTER HollenderG, Die britische Verfassung aus deutscher Sicht, in: Neue politische Literatur 17 (1972), S.372-388; Wolfgang J. MommSEN, Zur Entwicklung des Englandbildes der Deutschen seit dem Ende des 18. Jahrhunderts, in: Studien zur Geschichte Englands und der deutsch-britischen Beziehungen, hrsg. v. LOTHAR KetTenacker / Manfred Schlenke / Hellmut Seier, München 1981, S. 375-397; siehe auch DERS., Das Englandbild der Deutschen und die britische Sicht seit dem Ende des 18. Jahrhunderts, in: Hans Süssmuth (Hrsg.), Deutschlandbilder in Dänemark und England, in Frankreich und in den Niederlanden, Baden-Baden 1996, S. 215-234.

66 Leonhard LenK, Das Modell England in der bayerischen Verfassungsdiskussion zwischen 1770 und 1818, in: Gesellschaft und Herrschaft. Forschungen zu sozial- und landesgeschichtlichen Problemen vornehmlich in Bayern. Eine Festgabe für Karl Bosl zum 60. Geburtstag, München 1969, S. 271-299; WilHeLm BraunEDER, England als Vorbild in der österreichischen Verfassungsentwicklung des 19. Jahrhunderts, in: Staat - Souveränität - Verfassung, hrsg. v. Dietrich Murswiek / Ulrich Storost / Heinrich A. Wolff, Berlin 2000, S. 511-526. 
lenbasis rekonstruierte und untersuchte ${ }^{67}$, unternahm es Michael Maurer, in einer gediegenen und tiefschürfenden Studie das Verhältnis von „Aufklärung und Anglophilie in Deutschland“ anhand einer Reihe führender Repräsentanten des deutschen Geisteslebens in der zweiten Hälfte des 18. Jahrhunderts zu bestimmen ${ }^{68}$. Er beschränkte sich dabei nicht nur auf die Rezeption der englischen Verfassung, sondern rekonstruierte die deutsche Anglophilie ausführlich in allen ihren sozialen, ideengeschichtlichen, kunst- und kulturhistorischen Facetten. Kleinere Beiträge lieferten Renate Dopheide in ihrer Dissertation zum deutschen Republikanismus des späten 18. Jahrhunderts ${ }^{69}$, Eckart Pankoke und Michael Epkenhans mit Überblicksstudien zu klassischen Deutungsmustern deutscher Englandbilder des 18. und 19. Jahrhunderts ${ }^{70}$, schließlich Wolfgang von Hippel mit einer ergiebigen Regionalstudie zu Südwestdeutschland ${ }^{71}$.

Die neuesten Arbeiten stammen von Wolfgang Pöggeler, der 1995 einen thematisch und zeitlich weitgestreckten, vom Umfang her aber nur äußerst knappen - doch hier und da einige neue Resultate enthaltenden - Überblick zur Geschichte der „deutschen Wissenschaft vom englischen Staatsrecht“ zwischen 1748 und 1914 vorlegte $^{72}$; sodann von Uwe Wilhelm, der in einer wichtigen Darstellung den deutschen Frühliberalismus bis 1789 anhand des Leitfadens politischer Anglophilie untersuchte, dabei aber den Begriff des Frühliberalismus sehr weit, vielleicht etwas zu weit ausgedehnt hat ${ }^{73}$. Erwähnt zu werden

67 Sisko Haikala, „Britische Freiheit“ und das Englandbild in der öffentlichen deutschen Diskussion im ausgehenden 18. Jahrhundert, Jyväskylä 1985.

68 Michael Maurer, Aufklärung und Anglophilie in Deutschland, Göttingen u. a. 1987 (behandelt werden - in der Art einer geistesgeschichtlichen Gipfelwanderung - Justus Möser, Sophie von La Roche, Johann Wilhelm von Archenholz, Gebhard Friedrich August Wendeborn, Georg Christoph Lichtenberg, Johann Joachim Eschenburg, Johann Gottfried Herder und Georg Forster). - Siehe auch DERS., Nationalcharakter und Nationalbewußtsein. England und Deutschland im Vergleich, in: Volk - Nation - Vaterland, hrsg. v. Ulrich Herrmann, Hamburg 1996, S. 89-100.

69 Renate DopheIDE, Republikanismus in Deutschland: Studie zur Theorie der Republik in der deutschen Publizistik des späten 18. Jahrhunderts, phil. Diss. Bochum 1980, S.364ff.

70 EcKart Pankoke, „Englische Freiheit“. Klassische Deutungsmuster deutscher Englandbilder, in: Englischer Liberalismus im 19. und frühen 20. Jahrhundert, hrsg. v. KARL ROHE, Bochum 1987, S.33-65; Michael Epkenhans, Aspekte des deutschen Englandbildes 1800-1914: Vorbild und Rivale, in: Westfälische Forschungen 44 (1994), S. 329-342.

71 Wolfgang von Hippel, England in Südwestdeutschland. Britische Realität und deutsche Wahrnehmung während der ersten Hälfte des 19. Jahrhunderts, in: Das kontinentale Europa und die britischen Inseln. Wahrnehmungsmuster und Wechselwirkungen seit der Antike, hrsg. v. GOTTFRIED NiEdHART, Mannheim 1993, S. 118-138.

72 Wolfgang Pöggeler, Die deutsche Wissenschaft vom englischen Staatsrecht. Ein Beitrag zur Rezeptions- und Wissenschaftsgeschichte 1748-1914, Berlin 1995; dazu die Rezension des Verfassers in: in: Zeitschrift für Politik 44 (1997), S. $403 \mathrm{f}$.

73 Uwe Wilhelm, Der deutsche Frühliberalismus. Von den Anfängen bis 1789, Frankfurt a. M. u. a. 1995 (dazu die Rezension des Verfassers in: Zeitschrift für Politik 48 [2001], S.349-350); siehe auch Uwe Wilhelm, Der deutsche Frühliberalismus. Problem und Ergebnisskizze eines Forschungsprojektes, in: Jahrbuch zur Liberalismus-Forschung 5 (1993), S.155-161; den Arbeiten von Wilhelm folgt auch dessen Doktorvater HaNS 
verdient auch eine neue, umfassende Studie von Holger Krahnke, der auf eindrucksvoller Materialbasis die - von unübersehbar anglophilen Tendenzen geprägte - Entstehung und Entwicklung der Staats- und Politikwissenschaft an der Universität Göttingen vom späten 18. bis zum frühen 19. Jahrhundert rekonstruiert und untersucht hat ${ }^{74}$. Einige eher allgemein gehaltene Bemerkungen zur deutschen Anglophilie des 18. Jahrhunderts enthält ebenfalls ein 1998 erschienenes Werk von Ian Buruma ${ }^{75}$.

Über den eben skizzierten Forschungsstand beabsichtigt die folgende, auf einer deutlich breiteren Quellenbasis als alle bisherigen Arbeiten aufruhende Untersuchung in vier Hauptaspekten hinauszugehen. Zuerst einmal soll in einem sehr allgemeinen Sinne eine Antwort auf die Frage nach den Gründen für das - nicht nur im Inselreich, sondern ebenfalls in den fankophonen Ländern und Gebieten des Kontinents vorhandene - außerordentliche Interesse an der Verfassung von England versucht werden. Dies erfordert zunächst die Beantwortung einiger vorausgehender Fragen - etwa nach dem Beginn dieses Interesses und nach dessen Trägern, nach den Perspektiven, aus denen dieses Thema in den Blick geriet, nach den eigentlichen Schwerpunkten sowie den politischen Hintergründen und Motiven, schließlich auch nach den Formen, in denen dieser europäische, die nationalen Grenzen von Anfang an übersteigende Diskurs verlaufen ist.

Mit diesem ersten Teil soll aber auch, zweitens, die Frage nach den Quellen des deutschen Englandbildes, insbesondere der deutschen Rezeption der englischen Verfassung beantwortet werden. Wie die deutschsprachigen Quellen zeigen, waren es (nicht zuletzt mangels eigener Reiseerfahrung) in der Regel eine bestimmte Zahl englischer und französischer Autoren, deren Englandbilder in Deutschland ebenso intensiv wie folgenreich rezipiert worden sind, und zwar nicht nur einige wenige „Klassiker“ wie Rapin de Thoyras, Voltaire, Montesquieu, De Lolme oder Blackstone, sondern eine weit umfangreichere Zahl mehr oder weniger bekannter, heute teilweise vergessener zeitgenössischer Autoren der verschiedensten Provenienz ${ }^{76}$.

Drittens ist beabsichtigt, die deutsche Diskussion um die politische Ordnung Großbritanniens zwischen Glorious Revolution und dem Ende des Ancien Régime auf wesentlich breiterer Materialbasis als in der bisherigen Forschung zu

FEnske, Der moderne Verfassungsstaat. Eine vergleichende Geschichte von der Entstehung bis zum 20. Jahrhundert, Paderborn u. a. 2001, S. $127 \mathrm{ff}$.

74 Holger Krahnke, Reformtheorien zwischen Revolution und Restauration. Die gesammte Politik an der Universität Göttingen im ersten Drittel des 19.Jahrhunderts, Frankfurt a. M. u.a. 1999, bes. S.156ff. u. passim; als frühere, recht knappe Studie siehe bereits RichARD NÜRnberger, Die Lehre von der Politik an der Universität Göttingen während der französischen Revolution, Göttingen 1971.

75 IAn Buruma, Anglomania - A European Love Affair, New York 1998, bes. S. 50 ff. u. passim.

76 Da eine Reihe dieser Werke, vornehmlich englische, ins Deutsche übersetzt worden und vermutlich in dieser Form vorrangig rezipiert worden sind, finden die wichtigsten dieser zeitgenössischen Übersetzungen auch bereits im ersten Teil der vorliegenden Untersuchung Berücksichtigung. 
rekonstruieren. Friedrich Meineckes berühmte geistesgeschichtliche Methode, sich weitgehend auf die bedeutendsten Autoren eines bestimmten Themengebietes zu beschränken, also „eine Art Gratwanderung durch das Gebirge anzutreten und von einem der hohen Gipfel zum anderen hinüberzustreben, wobei dann ... auch Seitenblicke auf nicht besuchte Berge und Täler möglich sind“"77, sollte dabei ebenso vermieden werden wie andererseits die in einigen neueren Arbeiten zur Ideen- und Wissenschaftsgeschichte anzutreffende Vorgehensweise des „ausgeschütteten Zettelkastens“. Solche Arbeiten (in denen mit den Texten zugleich die Kontexte buchstäblich „zerschnitten“ werden) ertrinken gewissermaßen im angesammelten Material, weil deren Autoren das Prinzip der begründeten Auswahl manchmal zu wenig beherzigen und es deshalb auch versäumen, zusammenhängende Interpretationen zu einzelnen, für das in Rede stehende Thema besonders wichtigen Autoren vorzulegen. Denn die Frage, wer sich wann und wo, vor allem aber mit welcher Tendenz und welchem Urteil über die Verfassung Englands geäußert hat, darf in keinem Fall vernachlässigt werden. Wenn man davon ausgeht, daß „politisches Denken“ sich nicht nur auf einer abstrakt-theoretischen Ebene vollzieht, dann muß man einräumen, daß es auch lageabhängig ist, daß es reaktiv ist, $\mathrm{da}$ es von Interessen bestimmt wird und auch bestimmte Wirkungsabsichten verfolgt. Insofern ist es nicht nur legitim, sondern durchaus erforderlich, sich ebenfalls den Autoren selbst zuzuwenden und die Frage nach den persönlich-biographischen, nach den gegenwartspolitischen und nicht zuletzt auch nach den argumentativen Zusammenhängen ihrer Texte zu stellen.

Viertens erscheint es als notwendig, nicht ausschließlich die - fraglos wichtigen - anglophilen Autoren, die überzeugten Lobredner der vielgerühmten „britischen Freiheit“ in den Blick zu nehmen, wie dies fast alle - darunter die bedeutendsten - der neueren Arbeiten zum Thema tun ${ }^{78}$, sondern auch die zuweilen überaus scharfen Kritiker der politischen Zustände und Institutionen Großbritanniens einmal näher in den Blick zu nehmen, ihre Thesen zu prüfen und auch ihre jeweiligen, zum Teil sehr unterschiedlichen politisch-ideologischen Hintergründe aufzuhellen. Wenn es darum geht, die westeuropäische und die deutsche Diskussion über ein zentrales politisches Thema des 18. Jahr-

7 Friedrich Meinecke, Werke, Bd. III: Die Entstehung des Historismus, hrsg. v. CarL HinRICHS, München 1965, S.6. - Zur Problematik einer ausschließlich geistesgeschichtlichen Vorgehensweise siehe immer noch: Alfred Heuss, Kritische Bemerkungen zur „geistesgeschichtlichen“ Interpretation historisch-politischer Phänomene (1967), in: DERS., Gesammelte Schriften in drei Bänden, hrsg. v. Jochen BleIcken, Stuttgart 1995, Bd. III, S. 2062-2071; treffende Kritik an der Methode der „Gipfelwanderung“, die „das Anonyme, das Triviale, das Mittelmäßige, aber auch das zu Unrecht Vergessene“ übersieht, jetzt auch bei WOLFGANG BURGDORF, Reichskonstitution und Nation. Verfassungsreformprojekte für das Heilige Römische Reich Deutscher Nation im politischen Schrifttum von 1648 bis 1806, Mainz 1998, S. 30.

78 Das gilt vor allem für: Haikala, „Britische Freiheit“, Maurer, Aufklärung und Anglophilie, und Wilhelm, Der deutsche Frühliberalismus. 
hunderts umfassend zu rekonstruieren, dann muß die Fülle gerade der gegensätzlichen Thesen und der kontroversen Interpretationen angemessene Berücksichtigung finden.

\section{QUELLEN}

Das für diese Studie herangezogene Quellenmaterial entstammt den verschiedensten Gebieten ${ }^{79}$. Eine Informationsquelle ersten Ranges stellten im 18. Jahrhundert die Reiseberichte dar, die aus diesem Grunde ausdrückliche Beachtung gefunden haben. Selbst staatsrechtliche und politiktheoretische Schriften jener Zeit, ganz zu schweigen vom historisch-politischen Schrifttum, haben die wichtigsten Produkte gerade dieser Gattung immer wieder zitiert. Hinzu kommen ausgewählte, teilweise auch ins Deutsche übersetzte landeskundliche Handbücher, die dem Fremden, zumeist dem erstmaligen Englandbesucher (aber nicht nur ihm), näheren Aufschluß über die Verhältnisse auf den britischen Inseln vermitteln sollten. Die politischen Institutionen wurden hier in der Regel recht ausführlich berücksichtigt.

Als besonders ergiebige Quellen für die deutsche Rezeption der englischen Verfassung in diesem Zeitabschnitt haben sich - nach den im ersten Teil zu vergegenwärtigenden englischen und französischsprachigen Klassikern zum Thema - auch historische Darstellungen der englischen und der allgemeinen europäischen Geschichte erwiesen. Hinzu kommen die wichtigsten staatsrechtlichen Werke dieser Zeit, in der Jus und Historie - vor allem in Deutschland - ihren Weg oft noch gemeinsam zurücklegten ${ }^{80}$. Vor dem Aufstieg des strengen historistischen Denkens seit dem frühen 19. Jahrhundert haben sowohl Juristen wie auch Historiker ihre Werke oftmals in unübersehbarer Weise unter aktualitätsbezogenen und auch politisch-pädagogischen Gesichtspunkten verfaßt; die reine Erkenntnis um der Erkenntnis willen spielte dagegen eine eher untergeordnete Rolle.

In stärkerem Maße gilt dies natürlich für die beiden Bereiche der politischen Theorie und vor allem der politischen Tagespublizistik, in denen das britische Verfassungsmodell und die Idee einer „englischen Freiheit“ während des gesamten 18. Jahrhunderts eine eminente, in keinem Fall zu übersehende Rolle gespielt haben. Die im Zusammenhang der Tagespublizistik, aber auch der innerwissenschaftlichen Diskussion besonders wichtige Zeitschriftenliteratur konnte freilich auch nicht annähernd vollständig erfaßt werden; gewisse Schwerpunktsetzungen waren hier unumgänglich, zumal der voraussehbare

79 An dieser Stelle sei angemerkt, daß sämtliche in den folgenden Kapiteln enthaltenen Quellenzitate genau der jeweils vom Verfasser herangezogenen Vorlage folgen - einschließlich falsch gesetzter Akzente und fehlerhafter Orthographie sowie Interpunktion.

80 Klassisch hierzu immer noch: Notker Hammerstein, Jus und Historie. Ein Beitrag zur Geschichte des historischen Denkens an deutschen Universitäten im späten 17. und im 18. Jahrhundert, Göttingen 1972. 
Aufwand (angesichts der offenkundigen Redundanz ständig sich wiederholender Englandbilder und -klischees) in einem umgekehrten Verhältnis zum absehbaren Ertrag dieser Bemühungen gestanden hätte. Zudem konnte - nach gründlicher Durchsicht einiger repräsentativer Organe dieser Zeit - davon ausgegangen werden, daß in den meisten Zeitschriften kaum wesentliche Gedanken oder Ideen zu finden sind, die sich nicht auch in der reichhaltigen Buchliteratur jener Epoche niedergeschlagen haben ${ }^{81}$.

Um das Bild abzurunden und um nicht einzelnen Quellengattungen ein unverantwortbares Übergewicht zu geben, hat schließlich noch weiteres Material Berücksichtigung gefunden: Zum einen wurden, und zwar in beiden Teilen der vorliegenden Studie, zeitgenössische deutsche Übersetzungen der wichtigsten englischen politischen und historischen Literatur der Epoche herangezogen, die (auch angesichts der damals in Deutschland viel verbreiteteren französischen Sprach- und Lesekenntnisse) eine besonders wichtige Funktion bei der Vermittlung von Informationen über England gehabt haben. Den Einleitungen und Kommentaren der jeweiligen deutschen Übersetzer - unter denen sich zuweilen selbst sehr bedeutende Autoren, wie etwa Christian Garve, befanden ist dabei besondere Beachtung geschenkt worden. Vereinzelt wurden sodann ebenfalls wichtige private Zeugnisse, also Briefe, Tagebücher und andere seinerzeit nicht (oder vorerst nicht) für den Druck bestimmte persönliche Aufzeichnungen berücksichtigt, - auch um an einigen Beispielen die Diskrepanz dessen, was in Zeiten strenger Zensur öffentlich gesagt werden durfte und was verschwiegen werden mußte, sichtbar werden zu lassen. Endlich haben sich ebenfalls einzelne politische Dichtungen (darunter als zweifellos wichtigste einer der seinerzeit berühmten Staatsromane Albrecht von Hallers) als Quellen erster Ordnung für das deutsche Englandbild erwiesen.

Der für den Titel dieser Untersuchung gewählte Begriff „politisches Denken“ ist damit so weit wie möglich gefaßt. Gemeint ist also nicht eine Beschränkung auf politische Lehren oder Theorien im engeren Sinne, sondern die allgemeine politische Reflexion über alle Grundfragen politischer Existenz im weitesten Sinne - soweit sie dabei in irgendeiner Weise das Bild der Verfassung von England berücksichtigt hat.

\section{Fragestellungen}

Die folgende Untersuchung versteht sich als ideenhistorische, bewußtseinsgeschichtliche und diskursanalytische Studie zur Geschichte des politischen Denkens im West- und Mitteleuropa des 18. Jahrhunderts - also in der beginnenden

81 Eine wichtige Ausnahme bilden allerdings die unten (Kap. IX. 1.) ausführlich untersuchten „Göttingischen Anzeigen von gelehrten Sachen“ (später: „Göttingische gelehrte Anzeigen“), die als das wichtigste deutschsprachige Rezensionsorgan englischer und englandkundlicher Literatur in der zweiten Hälfte des 18. Jahrhunderts nicht vernachlässigt werden durften. 
Epoche des Übergangs von Alteuropa zur modernen Welt, vom Ancien Régime zum Revolutionszeitalter ${ }^{82}$. Im Unterschied zu vergleichbaren herkömmlichen Arbeiten sollen zentrale Aspekte dieses Denkens jedoch nicht anhand abstrakter politischer Kategorien (Freiheit, Despotismus, Monarchie, Republik, Souveränität, Gewaltenteilung, Repräsentation usw.) untersucht werden, sondern anhand der Darstellung und Rezeption eines konkreten Themas, der politischen Grundordnung und Verfassung von England. Es wird das Ziel verfolgt, in der Form von Textanalysen aus den verschiedensten Quellengattungen die in England selbst und in Westeuropa geführte Debatte über die Verfassung von England und, in einem zweiten Schritt, die deutschsprachigen Rezeptionsweisen zu erforschen, die dabei verwendeten Argumentationsformen zu untersuchen, nach Möglichkeit deren direkte oder indirekte Quellen zu ermitteln sowie die geistesgeschichtlichen, wissenschaftshistorischen und vor allem auch politisch-ideologischen Hintergründe nachzuzeichnen und zu analysieren.

Die Textanalyse hat sich - neben einer Untersuchung der Sprache und der verwendeten Begrifflichkeit - vor allem den unterschiedlichen semantischen Ebenen des untersuchten Materials zuzuwenden: Handelt es sich - erstens dem Anspruch des jeweiligen Autors nach um den Versuch einer bloßen literarischen Rekonstruktion im Sinne einer möglichst exakten Beschreibung von Wirklichkeit (etwa in einem Reisebericht oder einem englandkundlichen Werk), oder enthält der untersuchte Text bereits - zweitens - eine bewußt vorgenommene Problematisierung des Gegenstandes "englische Verfassung"? Etwa in dem Sinne, daß sie als politisches Vorbild oder negatives Gegenbild angesehen wird, daß sie als Demonstrationsobjekt zur Begründung eines (vielleicht propagandistischen Zwecken dienenden) politischen Arguments benötigt wird? Dient - drittens - ein Diskurs über jenen vielerörterten Gegenstand etwa „nur“ dem Anlaß, um (anknüpfend an reale Formen politischen Lebens) in allgemeiner Form bestimmte Grundfragen politischer Existenz zu diskutieren ${ }^{83}$, oder verfolgt - dies ist die vierte Ebene - eine Diskussion über die wirklichen oder vermeintlichen „britischen Freiheiten“, die Vor- und Nachteile der englischen Verfassung, etwa das verborgene Ziel, zentrale politische Probleme des

82 Zum Terminus der „Bewußtseinsgeschichte” siehe die Bemerkungen von HeINZ GollWITZER, Geschichte des weltpolitischen Denkens, Bd. II, Göttingen 1982, S.13, der „Bewußtseinsgeschichte“ als „Ideengeschichte“ definiert, „die die letzten fünfzig Jahre geschichtswissenschaftlicher Entwicklung rezipiert und verarbeitet hat", d. h., keine „quasimetaphysischen Assoziationen" weckt, sondern das politische Denken möglichst breit rezipiert, sich also nicht nur auf „Klassiker“ beschränkt, sondern individuelle wie kollektive Denkhaltungen in gleicher Weise in den Blick nimmt und ebenfalls den „politische[n] und gesellschaftliche[n] Kontext" in die eigenen Reflexionen und Analysen mit einbezieht.

83 So bemerkte kürzlich BETTY KEMP, Delolme, Jean Louis (1741-1806), in: Dictionary of Eighteen-Century British Philosophers, hrsg v. JoHN W. YOLTON / JOHN Vladimir PRICE / John StePhens, Bd. I, Bristol u. a. 1999, S. 260-262, hier S.261, daß, bezogen auf Kontinentaleuropa in der zweiten Hälfte des 18. Jahrhunderts, „the ... interest in the English constitution was very much part of interest in general political speculation". 
eigenen Landes in verdeckter Form zur Sprache zu bringen, - Probleme, die angesichts der Zensurpraxis jener Zeit ${ }^{84}$ unmöglich offen diskutiert werden konnten?

Diese Leitfragen der vorliegenden Untersuchung korrespondieren auf verschiedene Weise - und in unterschiedlicher Intensität - mit anderen, gegenwärtig eingehend diskutierten wissenschaftlichen Konzepten und Fragestellungen. Der jüngst von juristischer Seite formulierte Befund, daß die Entstehungsgeschichte gerade der neueren und neuesten Verfassungen „eindrucksvoll den hohen Grad gegenseitiger Beeinflussung der Staaten bei der Verfassungsgebung und Verfassungsänderung “85 dokumentiert, läßt sich auch in die Vergangenheit rückverlängern, wie etwa die aktuelle Forschung zu den vielfältigen Formen und Inhalten des Kulturtransfers in der neueren Geschichte eindrucksvoll zu zeigen vermag ${ }^{86}$. Über den - gleichwohl auch weiterhin wichtigen - Vergleich hinausreichend, geht es hier um den Nachweis, „daß Nationalkulturen nicht geschlossene Systeme waren, sondern oftmals erst im gegenseitigen Austausch ,erfunden“ wurden“"87. Die geschichtliche Entstehung des ,Eigenen“ ist jedenfalls ohne die Vergegenwärtigung der jeweiligen Auseinandersetzung mit dem ,Anderen' nicht angemessen zu begreifen.

Daneben sollen, vor allem im zweiten Teil der Arbeit, ebenfalls rezeptionsgeschichtliche Fragestellungen nicht vernachlässigt werden; die Ergebnisse der teilweise durchaus beachtlichen älteren wie auch der neueren Erforschung der deutsch-englischen Kulturbeziehungen und der deutschen Englandrezeption vor allem in den Bereichen Literatur, Geschichtsschreibung und Philosophie ${ }^{88}$ - sind als vergleichende Aspekte wenigstens gelegentlich mit zu beachten, um einen Blick für die Differenzierung zwischen unterschiedlichen Rezeptionsvor-

84 Vgl. dazu grundlegend: Bodo PlachtA, Damnatur - Toleratur - Admittitur. Studien und Dokumente zur literarischen Zensur im 18. Jahrhundert, Tübingen 1994.

85 Karl-Peter Sommermann, Staatsziele und Staatszielbestimmungen, Tübingen 1997, S. 409.

86 Als gute Einführung in die Problematik sowie als Forschungsüberblick mit reichen Literaturhinweisen siehe JOHANNES PAULMANN, Internationaler Vergleich und interkultureller Transfer. Zwei Forschungsansätze zur europäischen Geschichte des 18. bis 20. Jahrhunderts, in: Historische Zeitschrift 267 (1998), S. 649-685; wichtige Einzelbeiträge und Fallstudien zum deutsch-britischen bzw. deutsch-französischen interkulturellen Transfer sind enthalten in: Rudolf Muhs / Johannes Paulmann / Willibald Steinmetz (Hrsg.), Aneignung und Abwehr. Interkultureller Transfer zwischen Großbritannien und Deutschland im 19. Jahrhundert, Bodenheim 1998; ETIEnNE FrançoIs u. a. (Hrsg.), Marianne - Germania. Deutsch-französischer Kulturtransfer im europäischen Kontext - Les transferts culturels France-Allemagne et leur contexte européen 1789-1914, Leipzig 1998.

87 Paulmann, Internationaler Vergleich und interkultureller Transfer, S. 682.

88 Aus der älteren Forschung siehe etwa: МAX КосH, Über die Beziehungen der englischen Literatur zur deutschen im achtzehnten Jahrhundert, in: Verhandlungen der sechsunddreißigsten Versammlung deutscher Philologen und Schulmänner in Karlsruhe vom 27. bis 30. September 1882, Leipzig 1883, S. 95-117; JoHn Alexander Kelly, England and the Englishman in German Literature of the Eighteenth Century, New York 1921; LAWRENCE Marsden Price, Die Aufnahme englischer Literatur in Deutschland 1500-1960, Bern u. a. 
gängen, für verschiedene Themen, Formen, aber auch Geschwindigkeiten der Wahrnehmung, zu bekommen ${ }^{89}$. Endlich gilt es, den umgekehrten Blick von den britischen Inseln auf Deutschland im Auge zu behalten, um die reziproken Aspekte wechselseitiger Kulturbeziehungen und Rezeptionsvorgänge angemessen wahrnehmen zu können ${ }^{90}$. Aufschlußreich mag schließlich auch ein Seitenblick auf die Wahrnehmung der englischen Verfassung im Rußland jener Epoche ${ }^{91}$ sein, denn in der Tat gehört, wie jüngst mit Recht festgestellt wurde, „zu den interessantesten Problemen der Frühneuzeithistorie ... die Frage nach europäischen Wirkungszusammenhängen, die politische Grenzen transzendierten“92.

Darüber hinaus kann die eingehende Debatte um das britische politische Ordnungsgefüge des 18. Jahrhunderts als ein Sonderfall in der ideengeschichtlichen Konstruktion politisch vorbildlicher Formen des alteuropäischen Ge-

1961; - und aus der neueren besonders die Arbeiten von BERnHARD FABIAN, English Books and Their Eighteenth-Century German Readers, in: The Widening Circle. Essays on the Circulation of Literature in Eighteenth-Century Europe, hrsg. v. PAUL J. KorSHIN, o. O. (Philadelphia) 1976, S.117-196; DERS., The English Book in Eighteenth-Century Germany, London 1992; DERS., Selecta Anglicana. Buchgeschichtliche Studien zur Aufnahme der englischen Literatur in Deutschland im achtzehnten Jahrhundert, Wiesbaden 1994; sodann MANFRED KUEHN, Scottish Common Sense in Germany, 1768-1800. A Contribution to the History of Critical Philosophy, Kingston u.a. 1987; DERs., The German Aufklärung and British Philosophy, in: British Philosophy and the Age of Enlightenment, hrsg. v. STUART BROwn, London u. a. 1996, S. 309-331; REINHARD BRANDT, Die englische Philosophie als Ferment der kontinentalen Aufklärung, in: Europäische Aufklärung(en). Einheit und nationale Vielfalt, hrsg. v. Siegfried JütTner / Jochen Schlobach, Hamburg 1992, S. 66-79.

89 Mit Recht ist von einem der besten Kenner der Materie auf die gerade hier noch vorhandenen Forschungsdesiderate nachdrücklich hingewiesen worden: BERNHARD FABIAN, Nicolai und England, in: DERS.: Selecta Anglicana, S. 199: „Unsere Kenntnis vom Einfluß Englands auf das deutsche Geistesleben des späten achtzehnten Jahrhunderts ist noch immer rudimentär. Vor allem haben wird keine Vorstellung davon, welche Wirkung die Entdeckung Englands im einzelnen Fall gehabt hat, welche Prozesse sich dabei abgespielt und welche Veränderungen sich durch produktive Anverwandlung ergeben haben“.

90 Für das 18. Jahrhundert siehe jetzt den Überblick von FANIA Oz-SALZBERgER, Exploring the Germanick Body - Eighteen-Century British Images of Germany, in: Tel Aviver Jahrbuch für deutsche Geschichte 26 (1997), S. 7-23; aus der älteren Forschung ist immer noch grundlegend die Fallstudie von MANFRED SCHLENKE, England und das friderizianische Preußen 1740-1763. Ein Beitrag zum Verhältnis von Politik und öffentlicher Meinung im England des 18. Jahrhunderts, Freiburg u. a. 1963.

91 Siehe dazu neben der älteren Studie von Georg Sacke, Der Einfluß Englands auf die politische Ideologie der russischen Gesellschaft in der 2. Hälfte des XVIII. Jahrhunderts, in: Archiv für Kulturgeschichte 30 (1940), S. 85-105, auch Michael SCHIPPAN, Die englische Revolution und die nachrevolutionäre konstitutionelle Staatsform Englands in den Berichten russischer Zeitgenossen, in: Wissenschaftliche Zeitschrift der Humboldt-Universität zu Berlin; Gesellschaftswiss. R. 33 (1984), H. 3, S. 255-259.

92 Wolfgang Neugebauer, Zwischen Preußen und Rußland - Rußland, Ostpreußen und die Stände im Siebenjährigen Krieg, in: Zeitenwende? Preußen um 1800, hrsg. v. ECKHART Hellmuth / Immo Meenken / Michael Trauth, Stuttgart u. a. 1999, S. 43. 
meinwesens angesehen werden, stellt diese Verfassung doch (sofern sie nicht selbst als verkappte Form einer - aristokratischen - Republik aufgefaßt wurde) fast die einzige Form der Monarchie dar, die in diesen Kanon aufgenommen wurde, zu dem neben den klassischen Exempla Athen, Sparta und der Römischen Republik wenigstens zeitweilig auch die Schweiz, die Niederlande sowie die beiden - indes jeweils sehr verschiedenen - Adelsrepubliken Polen und Venedig gehörten ${ }^{93}$. In diesem Zusammenhang ist eine differenzierende Fragestellung vonnöten, die auch danach fragt, welche Elemente einer Verfassung auf welche Weise in einer bestimmten, historisch konkreten Situation rezipiert werden können.

Die Gründe für das im zweiten Teil zu thematisierende Interesse deutscher politischer Autoren vor $1789^{94}$ an der englischen Verfassung als Modellordnung und als Gegenbild waren, wie sich zeigen wird, überaus vielfältiger $\mathrm{Na}$ tur. Auf der einen Seite: Überdruß an der überalterten und schwerfälligen Reichsverfassung, Widerwillen gegen die Praxis des monarchischen Absolutismus (der oftmals keineswegs so „aufgeklärt“ war, wie man es sich eigentlich erhoffte), sodann der Wunsch nach Vorbildern für eigene Reformentwürfe im Hinblick etwa auf eine Verringerung der Standesschranken zwischen Adel und Bürgertum und einer verstärkten Anteilnahme des Bürgertums am Gemeinwesen auf der überregionalen, gesamtstaatlichen Ebene. - Aber auch die Kritiker vermochten ihre Rechnung aufzumachen: Die britische Verfassungsordnung konnte, in Erinnerung an die dortigen Revolutionen des 17. Jahrhunderts, als höchst problematisches Gegenmodell zu einer starken, Bürgerkriege verhindernden Staatsautorität, gleichfalls als (für Deutschland freilich unpraktikable)

93 Vgl. dazu neben den Hinweisen bei DopHeIDE, Republikanismus in Deutschland, S. $27 \mathrm{ff}$. , $60 \mathrm{ff}$. u. passim, bereits die klassische Untersuchung von Ranke zur Kritik am (durch Contarini im 16. Jahrhundert etablierten) Idealbild der venezianischen Verfassung, in: LEOPOLD VON RANKE, Venedig im sechszehnten Jahrhundert und im Anfang des siebzehnten, in: DERS.: Sämmtliche Werke, Bd.XLII, Leipzig 1878, S. 1-133, hier S.33ff.; WilLiaM J. Bouwsma, Venice and the Defense of Republican Liberty - Renaissance Values in the Age of the Counter Reformation, Berkeley u. a. 1968, bes. S. 144ff. u. passim; DERS., Venice and the political education of Europe, in: Renaissance Venice, hrsg. v. J. R. HALE, London 1973, S. 445-466; sodann ebenfalls die Fallstudien zur Rezeption Spartas und Athens von Elizabeth Rawson, The Spartan Tradition in European Thought, Oxford 1969, und Kyriacos Demetriou, In Defence of the British Constitution: Theoretical Implications of the Debate Over Athenian Democracy in Britain, 1770-1850, in: History of Political Thought 17 (1996), S. 280-297; eine umfassende Wirkungsgeschichte der athenischen Demokratie fehlt allerdings bis heute, vgl. Jochen BleICKEN, Die athenische Demokratie, 2. Aufl., Paderborn u. a. 1994, S. $581 \mathrm{f}$.

94 Siehe dazu statt vieler nur die beiden wichtigen Überblicksstudien von RUDOLF VIerhaus, Politisches Bewußtsein in Deutschland vor 1789, in: DERS.: Deutschland im 18. Jahrhundert. Politische Verfassung, soziales Gefüge, geistige Bewegungen, Göttingen 1987, S. 183-201, und Horst Möller, Kritik und Krise: Die Politisierung Deutschlands durch die Französische Revolution, in: Deutschland in den internationalen Beziehungen des 19. und 20. Jahrhunderts, hrsg. v. Walther L. Bernecker / VOlKer DotTERWeich, München 1996, S.25-42, mit jeweils weiteren ausführlichen Hinweisen. 
Alternative zu einem - die Rechte beider großer Konfessionen sicherstellenden - System des institutionellen Ausgleichs (im Reichstag zu Regensburg) angesehen werden ${ }^{95}$, - und schließlich ebenfalls als eine Ordnung, in der durchgreifende Reformen von oben (durch einen aufgeklärten Herrscher) wegen eines korrupten, fast allmächtigen Parlaments nicht möglich waren, oder die (durch zu viele dem einzelnen Bürger gewährte Freiheiten) im Endergebnis allgemeine Unsicherheit und ein hohes Maß an Kriminalität begünstigte.

Allgemeiner, und über das eben Gesagte hinausgehend, muß ebenfalls gefragt werden: Was für ein - weltanschauliches, politisches - Selbstbild entsteht im Spiegel des Anderen, in der Auseinandersetzung mit dem Anderen? Gelangt man zur präziseren, genaueren Selbsterkenntnis eher durch Vergleich oder gerade durch Abgrenzung?96 Und das gilt natürlich auch umgekehrt: Wie erscheint das Andere vor dem Hintergrund eigener - kontinentaler, deutscher Zustände und Erfahrungen? Wie weit vermögen, neben eigenen Voreingenommenheiten, Mißverständnisse, Übertragungsfehler, Ungenauigkeiten des Rezeptionsvorgangs das gegenseitige Bild des jeweils Anderen einzutrüben oder gar zu verzerren?

Schließlich wirft das Problem der Rezeption einer anderen politischen Verfassung in einem ganz allgemeinen Sinne die seit der Antike vielerörterte Frage nach der Vermittlung von Theorie und Praxis auf. Ist es überhaupt möglich, allgemeine Fragestellungen anhand des Beispiels einer historisch-konkreten und damit individuellen, einmaligen politischen Ordnung zu erörtern, oder bedarf eine allgemeine Erörterung derartiger Gegenstände geradezu der Ergänzung durch Rückbindung an geschichtlich Gegebenes, erfordert die abstrakte Reflexion über Grundprobleme des Politischen letztendlich eine, wie auch immer geartete, historisch-konkrete Bodenhaftung? Die politische Theoriebildung in der Tradition des Aristoteles - der bekanntlich die Grundprobleme der Ethik und der Politik nicht nur abstrakt behandelte, sondern auch anhand seiner Sammlung griechischer Verfassungsordnungen empirisch zu untermauern versuchte ${ }^{97}$ - scheint dies ebenso nahezulegen, wie die berühmten Erörterungen Montesquieus über die Teilung der Gewalten, die er im bekanntesten Abschnitt seines „L'Esprit des lois“ am Beispiel der „constitution d'Angleter-

95 So wurde bekanntlich die strikte Benachteiligung der Katholiken im kulturellen und politischen Leben Großbritanniens erst im Verlauf des 19. Jahrhunderts schrittweise beseitigt. - Zum Unterschied zwischen englischem Parlament und deutschem Reichstag siehe auch die Bemerkungen bei Friedrich Hermann SCHUberT, Die deutschen Reichstage in der Staatslehre der frühen Neuzeit, Göttingen 1966, S.381f.

96 So hat etwa Rudolf Vierhaus darauf hingewiesen, daß ,im gelehrten Vergleich ... der deutschen Zustände mit denen anderer Nationen (vor allem Englands und der Schweiz) Diskrepanzen des deutschen Lebens voll bewußt wurden“; DERS., Politisches Bewußtsein in Deutschland vor 1789, S. 185.

97 Vgl. hierzu immer noch Wilhelm OnCKen, Die Staatslehre des Aristoteles in historischpolitischen Umrissen. Ein Beitrag zur Geschichte der hellenischen Staatsidee und zur Einführung in die aristotelische Politik, Bde. I-II, Leipzig 1870-1875; Ndr. Aalen 1964, hier Bd. II, S. $317 \mathrm{ff}$. 
re“ - diese freilich als Idealtypus verstanden - abhandelte und erläuterte ${ }^{98}$. Daran knüpft sich die weitere Frage an: Wie theorieverhaftet und wie praxisbezogen muß, kann - oder vielmehr darf - politisches Denken sein?

Ein weiteres, wenngleich anders geartetes Vermittlungsproblem dürfte nicht weniger alt sein: Die Frage nach einem Gemeinwesen, das Ordnung und Freibeit in gleicher Weise sicherzustellen vermag, - denn als ein nachgerade ideales Modell hierfür ist die englische Verfassung immer wieder angesehen worden ${ }^{99}$. Zwei verschiedene Traditionen des Ordnungs- und des Freiheitsgedankens jeweils eine ältere und eine neuere - treffen hier zusammen: Einmal die antikmittelalterliche Vorstellung einer natürlich-göttlichen Weltordnung, eines integralen „Ordo“, der aller Anomie und jeder aus dieser entspringenden Anarchie entgegengesetzt ist ${ }^{100}$, zum anderen aber jener newere Ordnungsgedanke, der am Beginn der Konstituierung des frühmodernen Staates steht: Politische Ordnung als Ausdruck einer neutralen, aber politisch „absoluten“ Instanz zur Beendigung und Verhinderung konfessioneller (und anderer) Bürgerkriege ${ }^{101}$, -

98 Siehe dazu unten, Kap. IV. 1.

99 Es sei an dieser Stelle nur erinnert an die besonders kennzeichnenden Formulierungen von Friedrich Murhard, Englands Staatsverfassung, in: Staats-Lexikon oder Encyklopädie der Staatswissenschaften in Verbindung mit vielen der angesehensten Publicisten Deutschlands hrsg. v. CARl von RotTeck und CARL Welcker, Bd. V, Altona 1837, S. 84-171, hier S. 170: „Während man im größten Theile des übrigen Europa’s, von den Zeiten herab, wo die Anarchie des Mittelalters aufhörte, bis zu unseren Tagen, einen Zustand der Ordnung, entweder ohne Freiheit oder doch nur mit einem geringen Maaße von Freiheit erblickte, bot England, zumal seit seiner wohlthätigen glorreichen Revolution, die Erscheinung einer steten Vereinigung von Freibeit und Ordnung dar, in welcher die Principien des Fortschreitens und Erhaltens sich in einem glücklichen Gleichgewichte geltend machen konnten" (von mir hervorgehoben, H.-C.K.).

100 Vgl. dazu u.a. Hermann Krings, Ordo. Philosophisch-historische Grundlegung einer abendländischen Idee, Halle a. S. 1941; umfassend und gründlich zum politisch-philosophischen Problem der Ordnung nunmehr: AndREAS ANTER: Die Macht der Ordnung. Aspekte einer Grundkategorie des Politischen, Tübingen 2004.

101 Aus der außerordentlichen Fülle der Literatur gerade zu diesem Thema kann nur hingewiesen werden auf die grundlegenden und wegweisenden Studien von OTTO HINTZE, Gesammelte Abhandlungen, Bd.I: Staat und Verfassung. Gesammelte Abhandlungen zur allgemeinen Verfassungsgeschichte, hrsg. v. GERHARD OESTREICH, Göttingen 1970; GERHARD Oestreich, Geist und Gestalt des frühmodernen Staates. Ausgewählte Aufsätze, Berlin 1969; Michael Stolleis, Staat und Staatsräson in der frühen Neuzeit. Studien zur Geschichte des öffentlichen Rechts, Frankfurt a. M. 1990, jeweils passim. Allgemein auch R. M. MACIVER, The Modern State, London 1955; KenNeTH H. F. Dyson, The State Tradition in Western Europe. A Study of an Idea and Institution, Oxford 1980. - Zur Theoriegeschichte siehe u.a. DiETER WYDUCKEL, Princeps Legisbus Solutus. Eine Untersuchung zur frühmodernen Rechts- und Staatslehre, Berlin 1979 sowie die bereits als klassich anzusehende Studie von ReINHART Koselleck, Kritik und Krise. Eine Studie zur Pathogenese der bürgerlichen Welt (zuerst 1959), 3. Aufl. Frankfurt a. M. 1979. - Auf die breite neuere Diskussion zur frühmodernen „Staatsbildung“ kann an dieser Stelle nicht eingegangen werden; verwiesen sei nur auf die wichtige Bestandsaufnahme von REINHARD BLÄNKNER, „Absolutismus“ und „frühmoderner Staat“. Probleme und Perspektiven der Forschung, in: Frühe Neuzeit - Frühe Moderne? Forschungen zur Vielschichtigkeit von Übergangsprozessen, hrsg. v. RudoLF VIERHAUS und Mitarbeitern des Max-Planck-Instituts für Geschichte, Göttingen 1992, S. 48-74. 
theoretisch ausgearbeitet und auf den Begriff gebracht in den großen Werken von Bodin und Hobbes ${ }^{102}$.

Die ältere Tradition der Freiheitsidee ${ }^{103}$ wiederum besitzt verschiedene Wurzeln: Die antike Grundhaltung der Anti-Tyrannis ebenso wie die personale Freiheit des in letzter Konsequenz nur Gott unterworfenen christlichen Individuums, schließlich auch der Gedanke einer - auf die humanistische Rezeption der „Germania“ des Tacitus zurückgehenden - seit Urzeiten bestehenden „germanischen Freiheit“, die als ein späteres Deutungsmuster für die Verfassung von England sehr wichtig geworden ist ${ }^{104}$. Und daneben wiederum der neuere

102 Vgl. dazu statt vieler nur Helmut Quaritsch, Staat und Souveränität, Bd. I: Die Grundlagen, Frankfurt a. M. 1970, bes. S.243ff. u. passim; sowie Bernard Willms, Thomas Hobbes. Das Reich des Leviathan, München u. a. 1987, bes. S. $89 \mathrm{ff}$. u. passim.

103 Einen grundlegenden Überblick zur historischen Entwicklung des Verständnisses von Freiheit findet man in dem unfangreichen (von JOCHEN BLEICKEN, WeRnER CONZE, Christof Dipper, Horst GÜnther, Diethelm Klippel, Gerhard MaY und Christian MeIER verfaßten) Artikel „Freiheit“ I.-VIII., in: Geschichtliche Grundbegriffe. Historisches Lexikon zur politisch-sozialen Sprache in Deutschland, hrsg. v. Otto Brunner / Werner Conze / Reinhart Koselleck, Bd. II, 3. Aufl., Stuttgart 1994, S. 425-542.

104 Aus der Fülle der Literatur zu diesem Gegenstand seien hier erwähnt: William SEARLE HOLDSWORTH, The Influence of the Legal Profession on the Growth of the English Constitution, Oxford 1924, S.8ff.; ERWIN HölZle, Die Idee einer altgermanischen Freiheit vor Montesquieu. Fragmente aus der Geschichte politischer Freiheitsbestrebungen in Deutschland, England und Frankreich vom 16.-18.Jahrhundert, München u.a. 1925; Wolfgang SAmTleben, Die Idee einer altgermanischen Volksfreiheit im vormärzlichen deutschen Liberalismus, Hamburg 1935, S. 5-18; MARIE SCHÜTT, Das Germanenproblem in der englischen Geschichtsschreibung des 18. Jahrhunderts, in: Britannica et Americana, Bd.5, Hamburg 1960, S.7-48; Heinz GollwitZer, Zum politischen Germanismus des 19. Jahrhunderts, in: Festschrift für Hermann Heimpel zum 70. Geburtstag am 19. September 1971, hrsg. von den Mitarbeitern des Max-Planck-Instituts für Geschichte, Bd.I, Göttingen 1971, S. 282-356, hier S.293ff.; HildbuRg Hunke, Germanische Freiheit im Verständnis der deutschen Rechts- und Verfassungsgeschichtsschreibung, jur. Diss. Göttingen 1972; DietMar Willoweit, Von der alten deutschen Freiheit. Zur verfassungsgeschichtlichen Bedeutung der Tacitus-Rezeption, in: Vom normativen Wandel des Politischen, hrsg. v. Erk Volkmar Heyen, Berlin 1984, S.17-42; Catherine VolpilhaCAuger, Tacite et Montesquieu, Oxford 1985, passim; R. J. SMITH, The Gothic Bequest. Medieval Institutions in British Thought, 1688-1863, Cambridge 1987; UlRICH MUHLACK, Die Germania im deutschen Nationalbewußtsein vor dem 19. Jahrhundert, in: Beiträge zum Verständnis der Germania des Tacitus, Teil I, hrsg. v. HerberT JankUHN / DieTER TimPE, Göttingen 1989, S.128-154; neuerdings wichtig: KarL H. L. Welker, Altes Sachsen und koloniales Amerika. Naturrechtsdenken und Tacitusrezeption bei Justus Möser, in: Rainer Wiegels / Winfried Woesler (Hrsg.), Arminius und die Varusschlacht. Geschichte - Mythos - Literatur, Paderborn u. a. 1995, S. 323-344; Mathias Reimann, „In such forests liberty was nurtured“. Von den germanischen Wurzeln der anglo-amerikanischen Freiheit, in: Wirkungen europäischer Rechtskultur, hrsg. v. GERHARD KÖBLER / Hermann Nehlsen, München 1997, S. 933-951, und, auf die deutsche Diskussion bezogen, Barbara Stollberg-Rilinger, Vormünder des Volkes? Konzepte landständischer Repräsentation in der Spätphase des Alten Reiches, Berlin 1999, S.234ff. - Wichtig zum Zusammenhang ebenfalls noch LeONARD KRIEGER, The German Idea of Freedom. History of a Political Tradition, Boston 1957, sowie Hans MaIER, Das Freiheitsproblem in der deutschen Geschichte, Heidelberg 1992. 
Freiheitsgedanke, der - unter Berufung auf das Naturrecht und auf die Vernunftfähigkeit des Menschen - die fundamentale Autonomie des einzelnen Individuums, dessen Recht auf Unversehrtheit, Eigentum und ungehinderte Meinungsäußerung betont. Der Freiheitsdiskurs der Aufklärung ist hierdurch maßgeblich bestimmt worden ${ }^{105}$. Der ältere und der neuere Ordnungsbegriff wie auch das ältere und das neuere Freiheitsverständnis lassen sich allenfalls strikt definitorisch voneinander trennen. Historisch gesehen, gibt es - zumal in der frühen Neuzeit - keine „reine“ Ausprägung dieser Typen, sondern fast stets Mischformen: Auch für den neuzeitlichen Vertreter des Ordnungsstaates, den absoluten Monarchen, galt das „göttliche Recht“, über das er sich nicht hinwegsetzen durfte; und andererseits hatte sich auch der neuzeitliche „freie“ Mensch stets in das (wie auch immer im einzelnen geartete) Ordnungssystem eines Gemeinwesens einzufügen, das seine Freiheit im Rahmen dessen, was als sozial verträglich angesehen wurde, einschränken mußte.

Die Frage nach der Vermittlung der Extreme, der Vereinbarung von Ordnung und Freiheit, hat sehr alte Wurzeln in der europäisch-abendländischen Denktradition. Die bekannteste und zweifellos wirkungsmächigste dieser frühen Antworten findet sich bereits in der „Politik“ des Aristoteles, der die von ihm bevorzugte Staatsform der „Politie“ als eine Verfassung des Maßes und der Mitte, der richtigen Mischung zwischen Oligarchie und Demokratie definiert, gegründet auf die „mittleren“ Stände und daher nicht der Gefahr ausgesetzt, dem kaum erreichbaren Ideal der Aristokratie nachzustreben oder in das andere Extrem der Tyrannis zu verfallen ${ }^{106}$. Und Polybios - um die andere große Autorität der Antike auf diesem Gebiet zu nennen - sah in der Etablierung einer „gemischten Verfassung“, die er am Beispiel der Gesetzgebung des Lykurg sowie der Grundordnung der Römischen Republik exemplifizierte ${ }^{107}$, die ein-

105 Für die deutsche Aufklärung vgl. die materialreiche Fallstudie von JÜRGEN SCHLUMBOHM, Freiheit. Die Anfänge der bürgerlichen Emanzipationsbewegung in Deutschland im Spiegel ihres Leitwortes, Düsseldorf 1975.

106 Aristoteles, Politik, 1293b-1294b; 1295b-1297a.; vgl. auch OnCKen, Die Staatslehre des Aristoteles in historisch-politischen Umrissen, Bd. II, S. 220ff.; HANS vON ARNIM, Die politischen Theorien des Altertums, Wien 1910, S. 77 ff., bes. 95 ff.; Herman SiebeCK, Aristoteles, 4. Aufl., Stuttgart 1922, S.114ff.; Peter Weber-SCHÄFER, Einführung in die antike politische Theorie, Bd. II: Von Platon bis Augustinus, Darmstadt 1976, S. $37 \mathrm{ff} . ;$ DERS., Aristoteles, in: Klassiker des politischen Denkens, hrsg. v. Hans Maier / Heinz Rausch / Horst Denzer, Bd. I, 6. Aufl., München 1986, S. 45-69; Alexander Demandt, Der Idealstaat. Die politischen Theorien der Antike, 2. Aufl., Köln u. a. 1993, S. 123 ff.; CURTIS JoHNSON, Aristotele's Polity: Mixed or Middle Constitution?, in: History of Political Thought 9 (1988), S. 189-204; besonders wichtig ERnEST BARKER, Introduction, in: The Politics of Aristotle. Translated with an Introduction, Notes and Appendixes by ERNEST BARKER, London u. a. 1958, S. xi-lxxvi; Dietmar Herz, Die wohlerwogene Republik. Das konstitutionelle Denken des politisch-philosophischen Liberalismus, Paderborn u. a. 1999, S. 56ff.

107 Vgl. Polybios, Historien VI, 7ff.; VI, $11 \mathrm{ff}$.; vgl. Weber-SCHÄFER, Einführung in die antike politische Theorie, Bd.II, S.95ff., DemandT, Der Idealstaat, S. 209ff. - Zum Zusammenhang der antiken Mischverfassungslehre siehe vor allem PaUla Zillig, Die Theorie von der gemischten Verfassung in ihrer literarischen Entwicklung im Altertum 
zige Möglichkeit, aus dem Kreislauf der Verfassungen auszubrechen und zu einer dauerhaften Ordnung zu gelangen. Der Kampf um die „Verfassungsmitte“ durch „Verfassungsmischung“ wurde damit zu einem Grundthema der weiteren politischen Ideengeschichte Europas ${ }^{108}$.

$\mathrm{Daß}$ auf die Ära der politisch-konfessionellen Bürgerkriege und ihrer verheerenden Folgen für Europa eine Epoche verhältnismäßiger „Stabilität“ durch die - wenn auch vielerorts nur partielle - Ausbildung frühmodern-staatlicher Ordnungsstrukturen folgte ${ }^{109}$, war nur allzu verständlich. Jede Ordnung, die ein Minimum an Sicherheit verbürgte, erschien vielen Zeitgenossen immer noch besser als Anomie, Willkür und Anarchie: „Leviathan“ stellte ein kleineres Übel dar als „Behemot“. Mit der Zeit jedoch geriet das andere Extrem politischer Existenz, die Gefahr der Ausartung absoluter Herrschaftsstrukturen in den Despotismus, immer stärker in das Visier derjenigen, die über die Grundfragen der Politik nachdachten ${ }^{110}$. Die Vermeidung der despotischen Gefahren wurde, ebenso wie die Sicherung eines Mindestmaßes an verbürgter persönlicher und politischer Freiheit, im 18. Jahrhundert zu einem Grundthema politischer Reflexion ${ }^{111}$. Die Kritik am Despotismus - meist aus Gründen der Zensur am scheinbar fernliegenden Beispiel der „asiatischen Despotie“ zur Sprache gebracht ${ }^{112}$ - gehört, nicht nur bei Montesquieu ${ }^{113}$, zum Kernbestand politischen Argumentierens.

und ihr Verhältnis zur Lehre Lockes und Montesquieus über Verfassung, phil. Diss. Würzburg 1916; sowie grundlegend KURT VON FRITZ, The Theory of the Mixed Constitution in Antiquity. A Critical Analysis of Polybius' Political Ideas, New York 1954, bes. S. 60ff., und Wilfried NipPeL, Mischverfassungstheorie und Verfassungsrealität in Antike und früher Neuzeit, Stuttgart 1980, S. 30-158.

108 Diese Begriffe nach VIKTOR Wember, Verfassungsmischung und Verfassungsmitte. Moderne Formen gemischter Verfassung in der politischen Theorie des beginnenden Zeitalters der Gleichheit, Berlin 1977; zum historischen Hintergrund siehe auch den Überblick von Charles Howard McIlwain, The Growth of Political Thought in the West. From the Greeks to the End of the Middle Ages (1932), New York 1959.

109 Grundlegend hierzu jetzt die weit ausgreifende, eindrucksvolle Studie von WoLfGANG REINHARD, Geschichte der Staatsgewalt. Eine vergleichende Verfassungsgeschichte Europas von den Anfängen bis zur Gegenwart, München 1999, S.31ff. u. passim; vgl. neuerdings auch die Übersicht von LUISE SCHORN-SCHÜTTE, Staatsformen in der frühen Neuzeit, in: Alexander Gallus / Eckhard Jesse (Hrsg.), Staatsformen. Modelle politischer Ordnung von der Antike bis zur Gegenwart. Ein Handbuch, Köln u. a. 2004, S. 123-152.

110 Vgl. dazu u. a. Richard Koebner, Despot and Despotism: Vicissitudes of a Political Term, in: Journal of the Warburg and Courtauld Institutes 14 (1951), S. 275-302; HeLLA MANDT, „Tyrannis, Despotie“, in: Geschichtliche Grundbegriffe. Historisches Lexikon zur politisch-sozialen Sprache in Deutschland, hrsg. v. OTTO BRUNNER / WERNER CONZE / Reinhart Koselleck, Bd. VI, Stuttgart 1997, S. 651-706, bes. S. $674 \mathrm{ff}$.

111 Vgl.Stammler, Politische Schlagworte in der Zeit der Aufklärung, S. 209ff., 219ff. u. passim.

112 Siehe dazu etwa Patricia Springborg, The Contractual State: Reflections on Orientalism and Despotism, in: History of Political Thought 8 (1987), S. 395-433; neuerdings grundlegend JÜrgen Osterhammel, Die Entzauberung Asiens. Europa und die asiatischen Reiche im 18. Jahrhundert, München 1998, S. $271 \mathrm{ff}$.

113 Vgl. u. a. Arnd Morkel, Montesquieus Begriff der Despotie, in: Zeitschrift für Politik 13 (1966), S. 14-32; siehe zu Montesquieu auch unten, Kap. IV. 1. 
Dem entsprach wiederum eine Aufwertung des politischen Freiheitsgedankens und damit ebenfalls ein erneutes Interesse an den Grundformen eines Ordnung und Freiheit in gleicher Weise vereinbarenden Gemeinwesens. Aus diesem Grunde widmete man der englischen Verfassung - seit dem historischen Verfassungskompromiß der Glorious Revolution eine, wie es jedenfalls schien, stabile und im ganzen gut funktionierende Ordnung - auf dem Kontinent neue Aufmerksamkeit: Zum einen, weil sie, aus aristokratischen, monarchischen und demokratischen Elementen zusammengesetzt, eine perfekte Illustration für das Weiterwirken und die bleibende Gültigkeit der antiken Mischverfassungslehre zu sein schien ${ }^{114}$, und zum anderen, weil man in ihr die Hüterin einer spätestens seit dem hohen Mittelalter kontinuierlichen und damit in Europa einzigartigen Freiheitstradition zu sehen glaubte. Der Mythos der „ancient constitution“, auch jener der Magna Charta und der im Kern auf sie zurückgeführten „britischen Freiheit“, avancierte nicht nur zu einem zentralen Deutungsmuster der englischen politischen Ordnung, sondern auch zu einem Grundmotiv des europäischen politischen Denkens im 18. Jahrhundert ${ }^{115}$. Daher knüpfte auch die in dieser Epoche rapide ansteigende und in gewisser Weise kulminierende

114 Vgl. statt vieler CoRinne Comstock Weston, The Theory of Mixed Monarchy Under Charles I and After, in: The English Historical Review 75 (1960), S. 426-443, und NIPPEL, Mischverfassungstheorie und Verfassungsrealität in Antike und früher Neuzeit, S. 160-311; neuerdings auch HERZ, Die wohlerwogene Republik, S.71ff. - Grundlegend zum Fortwirken verschiedener Hauptformen antiken politischen Denkens im angelsächsischen Bereich sind die Arbeiten von JoHn G. A. Pocock, The Machiavellian Moment. Florentine Political Thought and the Atlantic Republican Tradition, Princeton 1975; DERS., Politics, Language, and Time. Essays on Political Thought and History, Chicago - London 1989; DERS., The Ancient Constitution and the Feudal Law. A Study of English Historical Thought in the Seventeenth Century, Cambridge 1990 (zuerst 1957); dt. Auswahl: JoHN G. A. Pocock, Die andere Bürgergesellschaft. Zur Dialektik von Tugend und Korruption, Frankfurt a. M. u. a. 1993; dazu die Rez. des Verfassers in: Arbitrium 15 (1997), S. 189-193. - Das große Verdienst Pococks liegt in dem ausführlichen Nachweis, daß die antik-frühneuzeitliche Tradition des „Bürgerhumanismus“ und dessen „politische Sprache“ das angelsächsische Denken bis zum Ende des 18. Jahrhunderts nicht weniger geprägt haben als der Frühliberalismus John Lockes. Gerade im 18.Jahrhundert vollzieht sich - ideenpolitisch gesehen - eine „single gigantic querelle between the individual as Roman patriot, self-defined in his sphere of civic action, and the individual in society of private investors and professional rulers ... It seems that the classical ideal quite simply did not die; that it was reborn with the great recovery of aristocracy which marks the later seventeenth and eighteenth centuries"; diese Zitate nach: JOHN G. A. Pocock, Authority and property. The question of liberal origins, in: DERs., Virtue, Commerce and History. Essays on Political Thought and History, Chiefly in the Eigheenth Century, Cambridge 1995, S. 51-71, hier S. 69f.

115 Die Literatur zum Thema ist immens; verwiesen sei an dieser Stelle statt vieler nur auf CONRAD BORnHAK, Genealogie der Verfassungen, Breslau 1935, S.7ff.; GerHARD RITTER, Wesen und Wandlungen der Freiheitsidee im politischen Denken der Neuzeit, in: DERS.: Vom sittlichen Problem der Macht. Fünf Essays, Bern 1948, S. 105-138; MaURICE Cranston, Some Aspects of the History of Freedom, in: Theorie und Politik, hrsg. v. Klaus von Beyme, Den Haag 1971, S. 18-34; Diethelm Klippel, Verfaßte Freiheit. Die Entdeckung der Freiheitsrechte als Verfassungsprinzip im 18. und 19. Jahrhundert, in: Reich, Regionen und Europa in Mittelalter und Neuzeit, hrsg. v. Paul-Joachim HeInig / 
allgemeine Diskussion über die Grund- und Freiheitsrechte des Menschen ${ }^{116}$ immer wieder an dieses historische Vorbild - und damit zugleich direkt oder indirekt auch an die bestehende englische Verfassung - an.

Das Thema dieser Verfassung und ihrer Wahrnehmung auf dem Kontinent, besonders im deutschen Sprach- und Kulturbereich, erhält eine weitere Bedeutung im Zusammenhang älterer und neuerer Diskussionen über die frühneuzeitliche "Staatsbildung“ und den eigentlichen Charakter des europäischen "Absolutismus“. Die vor einigen Jahren von Nicholas Henshall mit Vehemenz und entschiedener Einseitigkeit vorgetragene These vom „Mythus“ Absolutismus, der die Gleichartigkeit oder doch wenigstens Ähnlichkeit vieler kontinentaler und britischer Entwicklungen zugunsten eines nicht mehr haltbaren Konstrukts "Absolutismus" verkenne ${ }^{117}$, hat nicht nur in Großbritannien selbst, sondern vor allem auch in Deutschland starke Beachtung gefunden ${ }^{118}$. Neuere Untersuchungen zur frühneuzeitlichen Staatsbildung haben ebenfalls zu der Erkenntnis beigetragen, daß es auch im Großbritannien des 18. Jahrhunderts deutlich ausgeprägte staatlich-bürokratische Strukturen gegeben hat, die

Sigrid Jahns / Hans-Joachim Schmidt / Rainer Christoph Schwinges / Sabine WeFERS, Berlin 2000, S.149-169. - Zur „englischen Freiheit“ vgl. u. a. Roscoe Pound, The Development of Constitutional Guarantees of Liberty, New Haven u. a. 1957; WALTHER Hubatsch, Die englischen Freiheitsrechte, Hannover 1962; AnNe Pallister, Magna Charta. The Heritage of Liberty, Oxford 1971; Demetrios L. Kyriazis-Gouvelis, Magna Carta. Palladium der Freiheiten oder Feudales Stabilimentum, Berlin 1984; grundlegend auch die einschlägigen Aufsätze von GERALD STOURZH, Wege zur Grundrechtsdemokratie. Studien zur Begriffs- und Institutionengeschichte des liberalen Verfassungsstaates, Wien u.a. 1989, passim; Hans-Christoph SCHröder, Ancient Constitution - Vom Nutzen und Nachteil der ungeschriebenen Verfassung Englands, in: HANS VORLäNDER (Hrsg.), Integration durch Verfassung, Wiesbaden 2002, S. 137-212.

116 Diese Diskussion ist erfaßt in der monumentalen, an Gründlichkeit kaum zu übertreffenden Bibliographie von Günter BirTsch / Michael Trauth / Immo Meenken: Grundfreiheiten Menschenrechte 1500-1850. Eine internationale Bibliographie, Bde. I-V, Stuttgart u. a. 1991-1992 (das englisch- und das deutschsprachige Schrifttum in den Bänden I und II). - Wichtige Forschungsresultate enthalten die Bände: GÜNTER BIRTSCH (Hrsg.), Grund- und Freiheitsrechte im Wandel von Gesellschaft und Geschichte. Beiträge zur Geschichte der Grund- und Freiheitsrechte vom Ausgang des Mittelalters bis zur Revolution von 1848, Göttingen 1981; DERS. (Hrsg.), Grund- und Freiheitsrechte von der ständischen zur spätbürgerlichen Gesellschaft, Göttingen 1987. - Bedeutende ältere Arbeiten präsentiert der Band von Roman SCHNuR (Hrsg.), Zur Geschichte der Erklärung der Menschenrechte, Darmstadt 1964.

117 Nicholas Henshall, The Myth of Absolutism. Change and Continuity in Early Modern European Monarchy, London u. a. 1992; Zusammenfassung seiner Thesen bei DEMS., Early Modern Absolutism 1550-1700: Political Reform or Propaganda?, in: Der Absolutismus - ein Mythos? Strukturwandel monarchischer Herrschaft, hrsg. v. RonAlD G. Asch / HeINZ DuCHHARDT, Köln u. a. 1996, S. 25-53.

118 Vgl. vor allem die wichtige Besprechung von HeInz DuchHARDT, Absolutismus - Abschied von einem Epochenbegriff?, in: Historische Zeitschrift 258 (1994), S. 113-122, sowie den Sammelband von Asch / DuchHardt (Hrsg.), Der Absolutismus - ein Mythos?, bes. die Einleitung der Hrsg., S.3-24; zusammenfassend jetzt auch ERNST HiNRICHS, Fürsten und Mächte - Zum Problem des europäischen Absolutismus, Göttingen 2000. 
denen auf dem Kontinent in vielem vergleichbar sind. Anknüpfend an eine Vergegenwärtigung der von John Brewers Arbeiten ${ }^{119}$ ausgehenden neueren Forschungsresultate, gelangte Eckhart Hellmuth im Rahmen eines instruktiven Vergleichs zwischen England und Preußen zu dem Ergebnis, daß die „schlichte Dichotomie zwischen ,starkem ' preußischen Staat und ,schwachem' englischen Staat ... nicht länger mehr"120 stimme. Trotz fortwirkender Unterschiede (was etwa die jeweilige Bereitschaft zum staatlichen Interventionismus anbetreffe) seien die Ähnlichkeiten und strukturellen Analogien beider Systeme nicht mehr zu verkennen. In diesem Zusammenhang stellt sich durchaus die Frage, ob das starke kontinentale Interesse an der Verfassung von England nicht vielleicht ebenfalls hierdurch bedingt war - also durch eine größere Nähe, die später durch die einseitige Perspektive einer streng nationalstaatlich orientierten Historiographie ausgeblendet worden ist?

Freilich darf man die Gegenseite nicht aus dem Blickfeld verlieren. Eine andere, nicht weniger bedeutende neuere Forschungsrichtung, die vor allem mit dem Namen von Jonathan C. D. Clark verbunden ist, betont besonders stark die „alteuropäischen“, gewissermaßen traditionalistischen Elemente in der Lebenswirklichkeit und im politischen Denken Englands im 18. Jahrhundert, das Weiterwirken traditioneller Vorstellungen wie der „politischen Theologie“ des monarchischen Gottesgnadentums, die Bedeutung der Religion für das öffentliche Leben und des Patriarchalismus in der sozialen Wirklichkeit des britischen Ancien Régime ${ }^{121}$. Clarks Thesen - die wie diejenigen Henshalls und Brewers einer unverkennbaren (und wohl auch beabsichtigten) Einseitigkeit nicht entbehren - haben ebenfalls eine rege Diskussion ausgelöst ${ }^{122}$. Auch wer

119 Vor allem: JoHn BRewer, The Sinews of Power. War, money and the English state, 1688-1783, London u. a. 1989.

120 Eckhart Hellmuth, Der Staat des 18. Jahrhunderts. England und Preußen im Vergleich, in: Aufklärung 9 (1996), S. 5-24, hier S. 16; vgl. bes. auch S. 9 ff. - Hellmuth bringt zugleich einen wichtigen Überblick zur neuesten angelsächsischen Forschung über das Thema des frühneuzeitlichen Staats, auf den an dieser Stelle nur verwiesen werden kann. Siehe auch die Beiträge in: JoHn BREwer / ECKHART Hellmuth (Hrsg.), Rethinking Leviathan. The Eighteenth-Century State in Britain and Germany, Oxford 1999, sowie in: HARrY T. DICKINSON (Hrsg.), A Companion to Eighteenth-Century Britain, Oxford 2002.

121 Clark, English Society 1688-1832; DERS., Revolution and Rebellion. State and society in England in the seventeenth and eighteenth centuries, Cambridge 1990; DERS., Reconceptualizing eighteenth-century England, in: British Journal for Eighteenth-Century Studies 15 (1992), S. 135-139. - Mittlerweile ist eine stark überarbeitete und erweiterte Fassung von ClarKS „English Society“ (rev. ed. Cambridge 2000) erschienen.

122 Aus der Fülle der einschlägigen Beiträge siehe etwa LiNDA Colley, The Politics of Eighteenth-Century British History, in: Journal of British Studies 25 (1986), S. 359-379; JOANNA INNES, Jonathan Clark, Social History and England's „Ancien Regime”, in: Past \& Present 115 (May 1987), S. 165-200; Peter Wende, Revisionismus als neue Orthodoxie? Parlament und Revolution in der modernen englischen Historiographie, in: Historische Zeitschrift 246 (1988), S. 89-106; ROY PORTER, Georgian Britain: an ancien régime?, in: British Journal for Eighteenth-Century Studies 15 (1992), S. 141-144; William A. SPECK, The eighteenth century: England's ancien régime?, in: British Journal of Eighteenth-Century Studies 15 (1992), S. 131-133. 
Clarks Schlußfolgerungen nicht in allen Teilen beistimmt, wird seine - ältere Einseitigkeiten korrigierenden und viele bisher unberücksichtigte Quellen einbeziehenden - Forschungen nicht ignorieren können. Für manche Schlußfolgerungen aus Clarks Thesen (und gegen eine Überschätzung der britischen „Staatlichkeit“ des 18. Jahrhunderts) spricht schließlich auch die von Kenneth Dyson und neuerdings noch einmal von Neville Johnson hervorgehobene Tatsache, daß es einen eigentümlichen Staatsbegriff und ein spezifisches Staatsverständnis (auch ein dazugehöriges Staats- und Beamtenethos) im angelsächsischen Bereich während jener Epoche nicht gegeben hat - und in gewisser Hinsicht bis heute nicht gibt ${ }^{123}$.

Man tut also gut daran - trotz aller neuerlich von der Forschung zutage geförderten Analogien - die früher im Anschluß an die verfassungsgeschichtlichen Studien Otto Hintzes breit diskutierten Unterschiede zwischen britischer und kontinentaler Staatsbildung nicht aus den Augen zu verlieren. Ohne auf stark zeitbedingte (und in der Sache ohnehin verfehlte) frühere Dichotomien etwa zwischen einem „deutschen und westeuropäischen Staatsbegriff“ oder auch auf übertriebene Abgrenzungen zwischen „kontinentaler“ und „insularer" Staatsbildung zurückgreifen zu wollen ${ }^{124}$ - denen auf der angelsächsischen Seite übrigens das sorgsam gehegte und erst neuerlich in Frage gestellte Bild von der freiheitlichen englischen „Barriere gegen den Absolutismus“ entsprach $^{125}$-, bleibt die Einsicht Hintzes unüberholt, daß der verstärkte Zwang

123 Vgl. Dyson, The State Tradition in Western Europe, bes. S.186ff. u. passim; Neville JoHnSON, Über den Begriff des Staates aus vergleichender Sicht, in: Staat, Politik, Verwaltung in Europa, hrsg. v. Rudolf Morsey / Helmut Quaritsch / HeInRICH Siedentopf, Berlin 1997, S. 167-180, bes. S.169f., 179f.

124 Genannt seien etwa Heinrich OtTo Meisner, Deutscher und westeuropäischer Staatsbegriff in verfassungsgeschichtlicher Entwicklung, in: Deutsche Rundschau 169 (1916), S. 65-76, 244-255; GEORG BrodnitZ, Kontinentale und insulare Staatsbildung, in: Zeitschrift für die gesamte Staatswissenschaft 78 (1924), S. 19-70; EbERHARd KesSel, Der ,Inselstaat' in der Geschichte, in: Die Welt als Geschichte 10 (1950), S. 168-186.

125 Vgl. etwa Charles Howard McIlwain, The English Common Law, Barrier Against Absolutism, in: The American Historical Review 49 (1943/44), S.23-31; LORD WRIGHT, Liberty and the Common Law, in: The Cambridge Law Journal 9 (1945/47), S.2-16; William Searle Holdsworth, Central Courts of Law and Representative Assemblies in the Sixteenth Century (1912), in: DERS.: Essays in Law and History, hrsg. v. ARTHUR L. Goodhart / Harold G. Hanbury, Oxford 1946, S.37-70, bes. S.68ff.; Caroline RobBins, Why the English Parliament survived the Age of Absolutism. Some Explanations offered by Writers of the $17^{\text {th }}$ and $18^{\text {th }}$ Centuries, in: $\mathrm{X}^{\text {th }}$ International Congress of Historical Sciences Rome, 1955. Studies presented to the International Commission for the History of Representative and Parliamentary Institutions, XVIII, Louvain u.a. 1958, S.199-213; Carl JOACHIM FrIedrICH, Konstitutionalismus gegen Absolutismus, in: DERS.: Zur Theorie und Politik der Verfassungsordnung. Ausgewählte Aufsätze, Heidelberg 1963, S.36-48. - Dagegen neuerdings Michael Mendle, Parliamentary souvereignity: a very English absolutism, in: Nicholas PhilliPson / QuENTin SKINNER (Hrsg.), Political Discourse in Early Modern Britain, Cambridge 1993, S. 97-119; die ältere Auffassung wird weiterhin vertreten von SAMUEL E. FINER, The History of Government, Bd. III: Empires, Monarchies and the Modern State, Oxford 1999, S.1307ff., der "two traditions“ unterscheidet: „Absolute versus Parliamentary Monarchy“ (ebd., S. 1307). 
zur militärischen Selbstverteidigung manche Kontinentalstaaten (wie etwa Preußen) dazu geführt hat, bestimmte Formen der Militärverfassung zu entwickeln, die mit der jeweiligen Staatsverfassung untrennbar verbunden waren und eine Entwicklung zur parlamentarischen Monarchie nach britischem Vorbild lange Zeit verhindert haben ${ }^{126}$. Liegt hierin vielleicht einer der Hauptgründe dafür, daß die englische Verfassung des 18. Jahrhunderts nicht nur als Vorbild, sondern vielfach auch als Gegenbild empfunden worden ist, als negative Kontrastfolie zur Rechtfertigung kontinentaler Staatsautorität?

Otto Hintze hat sich auch immer wieder auf ein von John Robert Seeley formuliertes historisch-politisches "Gesetz" berufen ${ }^{127}$, dem entsprechend ein wohlhabendes, mit reichlich „Ausdehnungsraum“ versehenes Gemeinwesen seinen Bewohnern größere persönliche und politische Freiheiten gewähren könne als ein Staatsgebilde, das sich ständig gegen schwere äußere Bedrängnisse zu wehren habe und daher auf eine starke Regierung nicht verzichten könne; Seeley stellte fest: „It is reasonable therefore to conjecture that the degree of government will be directly proportional, and that means that the degree of liberty will be inversely proportional, to the degree of pressure"128. Diese These hat sich Otto Hintze zu eigen gemacht; so konnte er 1911 konstatieren: „Die insulare Sicherheit auf der einen Seite, der Zwang zu militärischer Bereitschaft auf der andern Seite kennzeichnen die verschiedenartigen Lebensbedingungen, denen sich die Regierungsform hüben und drüben angepaßt hat"129.

Es ist wenig bekannt, daß Hintze und Seeley mit diesem „Inselargument“ bereits in einer längeren Tradition standen. Tatsächlich scheint - im Anschluß

126 Vgl. OTTO Hintze, Staatsverfassung und Heeresverfassung, in: DERS.: Gesammelte Abhandlungen, Bd.I: Staat und Verfassung. Gesammelte Abhandlungen zur allgemeinen Verfassungsgeschichte, hrsg. v. GerHARD OESTREICH, Göttingen 1970, S. 52-83, bes. S.77f.; DERS., Das monarchische Prinzip und die konstitutionelle Verfassung, in: ebd., S.359-389, bes. S. 362 ff.; DERS., Das Verfassungsleben der heutigen Kulturstaaten, in: ebd., S. 390-423, bes. S. 408 ff.; DERS., Machtpolitik und Regierungsverfassung, in: ebd., S. 424-456, bes. S. 430ff.

127 Vgl. HinTZE, Gesammelte Abhandlungen, Bd.1: Staat und Verfassung, S. 366, 411, 433, 506; DERS., Unser Militarismus. Ein Wort an Amerika, in: Internationale Monatsschrift für Wissenschaft, Kunst und Technik 9 (1914), H. 4, Sp.209-220, hier Sp.213f.; DERS., Deutschland und das Weltstaatensystem, in: OtTo HintZe / Friedrich Meinecke / Hermann Oncken / Hermann Schumacher (Hg.), Deutschland und der Weltkrieg, Leipzig u. a. 1915, S. 3-51, hier S. 5f.

128 JoHn Robert Seeley, Introduction to Political Science - Two Series of Lectures (zuerst 1896), London 1914, S.131; weiter heißt es: „In other words, given a community which lives at large, in easy conditions and furnished with abundant room, you may expect to find that community enjoying a large share of liberty; given a community which has to maintain itself against great difficulties and in the midst of great dangers, you may expect to find in it little liberty and a great deal of government" (ebd.).

129 HintZe, Das monarchische Prinzip und die konstitutionelle Verfassung, S. 365; andere deutsche Zeitgenossen sind Hintze hierin gefolgt; erwähnt sei nur GuSTAV SCHMOLLER, Herkunft und Wesen der deutschen Institutionen, in: Deutschland und der Weltkrieg, hrsg. v. Otto Hintze / Friedrich Meinecke / Hermann Oncken / Hermann SchuMACHER, 2. erw. Aufl., Leipzig u. a. 1916, Bd. I, S. 199-231, hier S. 200. 
an einen knappen Hinweis Samuel Pufendorfs ${ }^{130}$ - Immanuel Kant einer der ersten deutschen Autoren gewesen zu sein, der 1798, im 2. Abschnitt seines „Streit[s] der Fakultäten“, dieses später so bekannte Argument formuliert hat. Zwar insistierte der Philosoph auch in dieser Schrift darauf, „daß diejenige Verfassung eines Volks allein an sich rechtlich und moralisch-gut sei, welche ihrer Natur nach so beschaffen ist, den Angriffskrieg nach Grundsätzen zu meiden, welche keine andere als die republicanische Verfassung, wenigstens der Idee nach, sein kann“, doch es sei „aber hiermit nicht gemeint, daß ein Volk, welches eine monarchische Constitution hat, sich damit das Recht anmaße, ja auch nur in sich geheim den Wunsch hege, sie abgeändert zu wissen; denn seine vielleicht sehr verbreitete Lage in Europa kann ihm jene Verfassung als die einzige anempfehlen, bei der es sich zwischen mächtigen Nachbaren [sic] erhalten kann“131. - Bismarck und andere griffen dieses Argument erneut auf ${ }^{132}$, und von späteren deutschen, aber auch britischen Autoren ist es - bis in die Zeit nach dem Zweiten Weltkrieg - immer wieder verwendet worden ${ }^{133}$. Nun ist dieses einst sehr populäre „Inselargument“ durchaus mit Blick auf das historische Gedächtnis der Engländer, auf die stets wache Erinnerung an „the Norman conquest" des Jahres 1066 (bekanntlich nicht die erste erfolgreiche Eroberung Englands), und ebenfalls auf immer wieder periodisch auftauchende Invasionsängste zu relativieren. Doch andererseits hat man auch in England selbst, und zwar bereits lange vor Seeley, die Vorzüge eines sicheren Insel-

130 Vgl. Samuel Pufendorf, Einleitung zu der Historie der vornehmsten Reiche und Staaten / so jetziger Zeit in Europa sich befinden. Zum vierdten mal gedruckt und verbessert, Frankfurt a. M. 1699, S.319f.; dazu auch unten, Kap. VI. 2.

131 Immanuel Kant, Gesammelte Schriften, hrsg. v. d. Königlich Preußischen Akademie der Wissenschaften, Bde. I-XXIX, Berlin u. a. 1910-1983, hier Bd. VII, S. 85, 86, Anm. *.

132 Vgl. Bismarck, Die gesammelten Werke, Bd. I, S. 374, wo ausdrücklich auf Englands „gesicherte ... Lage nach außen hin" verwiesen wird.

133 Vgl. u. a. MARcKs, Deutschland und England in den großen europäischen Krisen seit der Reformation, S. 49; CONRAD BORNHAK, Die weltgeschichtliche Entwicklung des Konstitutionalismus, in: Internationale Wochenschrift für Wissenschaft, Kunst und Technik 2 (1908), Sp. 427-438, hier Sp. 432; MEISNER, Deutscher und westeuropäischer Staatsbegriff, S.74; Hermann OncKen, Über die Zusammenhänge zwischen äußerer und innerer Politik, Leipzig u. a. 1919, S.37; BrodNITZ, Kontinentale und insulare Staatsbildung, bes. S. 40, 56 u. passim; CARL SchmitT, Verfassungslehre (1928), 6. Aufl., Berlin 1983, S. 50, 54. - Aufschlußreich noch die (1965 getroffene) Feststellung von JenNings, Die Umwandlung von Geschichte in Gesetz, S. 25: „Eine Evolution ist in England möglich gewesen, weil England eine kleine Insel ist, nur schwer angreifbar aus Gründen der Witterung und ausgestattet mit hervorragenden Häfen, die zu einer sich ausweitenden Welt Zugang verschafften". Auch Carl JoACHIM Friedrich, Constitutional Government and Democracy. Theory and Practice in Europe and America, 4. Aufl., Waltham, Mass. u. a. 1968, S. 61, betont, "that there is to be noted an interdependence between the growth of constitutional liberty and the absence of a standing army which decisively influenced the British development". - Zum Zusammenhang vgl. auch - mit Blick auf die Gegenwart - den instruktiven Essay von KeITH RobBins, Insular Outsider? ,British History' and European Integration, in: DERS.: History, Religion and Identity in Modern Britain, London u. a. 1993, S. 45-57. 
daseins gerühmt - schon Shakespeare verklärte seine Heimat als „That waterwalled bulwark, still secure / And confident from foreign purposes "134. Außerdem hat jenes Argument im politischen Denken und in der Einschätzung der englischen Verfassung eine bedeutende Wirkung gehabt ${ }^{135}$ - übrigens bis in die zweite Nachkriegszeit hinein ${ }^{136}$ - und darf daher im Rahmen der Fragestellung dieser Untersuchung nicht vernachlässigt werden.

Das Zeitalter kurz vor und vor allem während der „demokratischen Revolution“ im letzten Drittel des 18. Jahrhunderts ${ }^{137}$ wurde sowohl in Großbritannien wie auch auf dem Kontinent (und natürlich ebenfalls in Nordamerika) durch eine überaus intensive Diskussion über Bedeutung, Sinn, Zweck und

134 ShAKESPEARE, King John, II/1, 27-28. - Vgl. aus der politisch-historischen Literatur z. B. die Bemerkungen bei Roger ACHerley, The Britannic Constitution: Or, The Fundamental Form of Government in Britain ..., London 1727, S. iv; Lord George LyTtelton, The Persian Letters (being Letters of a Persian in England to His Friend in Isphahan, originally published in London in 1735), hrsg. v. RODERICK BOYD PORTER, Cleveland, Ohio 1988, S.76 (Nr.54); Henry St. John Viscount Bolingbroke, The Idea of a Patriot King (1738), in: DERS., Works, hrsg. v. DAVID MALLET, Bd. III, London 1754; Ndr. Hildesheim 1968, S. 106; John Chamberlayne, Magnæ Britannix Notitia: or, the Present State of Great Britain. With diverse Remarks Upon The Ancient State Thereof, London 1745, S. 50: ,... England, which is like a huge Fortress, or a garrison'd Town, fenced not only with strong Works, and a wide and deep Ditch, the Sea, but guarded also with excellent Out-works, the strongest and best built Ships of War in the World ...", und ADAm SMITH, Lectures on Jurisprudence, hrsg. v. R. L. Meek / D. D. Raphael / P. G. Stein, Oxford 1978, S. 265: "The absolute power of the sovereigns has continu'd ever since its establishment in France, Spain, etc. In England alone a different government has been established from the natural course of things ... The dominions were entirely surrounded by the sea, which was on all hands a boundary from its neighbours. No foreign invasion was therefore much to be dreaded“. - Zu Acherley, Lyttelton, Chamberlayne, Bolingbroke und Smith siehe auch unten, Kap. III. 2.; III. 9.; III. 5.; V. 5.

135 Pars pro toto sei hier nur verwiesen auf die Bemerkungen bei Paul RaPin DE ThoYras, Dissertation sur l'Origine du Gouvernement d'Angleterre, et Sur la Naissance, les Progrès, les Vûës, les Forces, les Intérêts, E les Caractéres des deux Partis des Whigs \& des Torys (zuerst La Haye 1717), erneut abgedruckt in: DERS., Histoire d'Angleterre. Seconde édition, Bd.XI, Den Haag 1749, S. 47-107, hier S. 88: „La Grande-Bretagne est une Isle, qui ne peut guéres être attaquée à l'improviste ..."; [JEAN BERNARD LE BLANC], Lettres de Monsieur L'Abbé Le Blanc, concernant le gouvernement, la politique et les moeurs des Anglois et des Francois, Bd. I, Amsterdam 1747, S. 4; außerdem (ohne sich direkt auf England zu beziehen, aber unverkennbar darauf anspielend) CHARLES LOUIS DE SECONDAT DE Montesquieu, Oeuvres complètes, hrsg. v. Roger Caillois, Bd.II, Paris 1951, S. 534 (De l'Esprit des Lois XVIII, 5): „Les peuples des îles sont plus portés à la liberté que les peuples du continent. ... la mer les sépare des grands empires, et la tyrannie ne peut pas s'y prêter la main; les conquérants sont arrêtés par la mer; les insulaires ne sont pas enveloppés dans la conquête, et ils conservent plus aisément leurs lois"; sowie Voltaire, Oeuvres complètes, avec des remarques et des notes historiques, scientificques et littéraires, Bd. LV, Paris 1826, S. 441 (Dictionnaire philosophique, „Gouvernement“): „N'est-ce point que, l'Angleterre étant une île, le roi n'a pas besoin d'entretenir continuellement une forte armée de terre, qui serait plutot employée contre la nation que contre les étrangers?“".

136 Vgl. BRYANT, The Story of England. Makers of the Realm, S. 20.

137 Der Begriff folgt R. R. Palmer, The Age of the Democratic Revolution. A Political History of Europe and America, 1760-1800, Bde. I-II, Princeton 1959-64. 
Grenzen der „Verfassung“ bestimmt ${ }^{138}$. Dabei ging es nicht nur und auch nicht in erster Linie, wie aus späterer Perspektive unhistorisch suggeriert werden kann, um eine Grundlegung des modernen liberalen Verfassungsstaates ${ }^{139}$, sondern - im Kontext dieser Epoche - viel eher um Fragen nach dem angemessenen Anteil der Stände oder des „absoluten“ Königtums an der Herausbildung frühmoderner politischer Strukturen ${ }^{140}$, um die Frage nach den Vorzügen oder Nachteilen republikanischer Staatsmodelle ${ }^{141}$, um die Frage nach den Möglichkeiten einer Fortentwicklung ständisch geprägter Gemeinwesen im Hinblick auf repräsentative parlamentarische Institutionen ${ }^{142}$, auch um die Frage nach einer durchgreifenden inneren Reform der Verfassungsstrukturen des Alten Reiches ${ }^{143}$, - aber auch um die Möglichkeiten eines langsamen evolutionärkontinuierlichen (statt eines revolutionären) Verfassungswandels, etwas später schließlich ebenfalls um die Frage, ob ein Verfassungsstaat auch auf einer ungeschriebene Verfassung beruhen könne oder in jedem Fall einer eigentlichen Verfassungsurkunde bedürfe ${ }^{144}$. Der Kontext dieser (hier nur äußerst knapp

138 Vgl. aus der Fülle der Literatur u. a. HeRbert SchambecK, Der Verfassungsbegriff und seine Entwicklung, in: Festschrift für Hans Kelsen zum 90. Geburtstag, hrsg. v. Adolf J. Merkl / René Marcic / Alfred Verdross / Robert Walter, Wien 1971, S. 211-241; allgemein auch STOURZH, Wege zur Grundrechtsdemokratie, passim. - Für Deutschland siehe u. a. Heinrich OtTo MeIsner, Staats- und Regierungsformen in Deutschland seit dem 16. Jahrhundert, in: Zeitschrift für die gesamte Staatswissenschaft 77 (1951/52), S. 225-265; DERS., Verfassung, Verwaltung, Regierung in neuerer Zeit, Berlin (-Ost) 1962; Eberhard SCHMidT-Assmann, Der Verfassungsbegriff in der deutschen Staatslehre der Aufklärung und des Historismus. Untersuchungen zu den Vorstufen eines hermeneutischen Verfassungsdenkens, Berlin 1967; Mathias Roggentin, Über den Begriff der Verfassung in Deutschland im 18. und 19. Jahrhundert, jur. Diss. Hamburg 1978; ERNSTWOLFGANG BÖCKENFÖRDE, Geschichtliche Entwicklung und Bedeutungswandel der Verfassung, in: DERS., Staat, Verfassung, Demokratie. Studien zur Verfassungstheorie und zum Verfassungsrecht, Frankfurt a. M. 1991, S.29-52; umfassend und gründlich: HeINZ Mohnhaupt / Dieter Grimm, Verfassung. Zur Geschichte des Begriffs von der Antike bis zur Gegenwart, Berlin 1995.

139 So etwa, mit Blick auf die frühe angelsächsische Theorieentwicklung, MANFRED BROCKER, Die Grundlegung des liberalen Verfassungsstaates. Von den Levellern zu John Locke, Freiburg i. Br. u. a. 1995.

140 Siehe dazu etwa Horst Dreitzel, Absolutismus und ständische Verfassung in Deutschland. Ein Beitrag zu Kontinuität und Diskontinuität der politischen Theorie in der frühen Neuzeit, Mainz 1992.

141 Dazu DopheIDe, Republikanismus in Deutschland, passim.

142 Einen Überblick über den Stand der mittlerweile sehr umfangreichen Forschung zu diesem Thema geben neuestens Wolfgang Neugebauer, Landstände im Heiligen Römischen Reich an der Schwelle zur Moderne. Zum Problem von Kontinuität und Diskontinuität um 1800, in: Reich oder Nation? Mitteleuropa 1780-1815, hrsg. v. HeInz DuchHardt / Andreas Kunz, Mainz 1998, S.51-86, und Stollberg-Rilinger, Vormünder des Volkes?, passim.

143 Hierzu vgl. neuerdings die grundlegende Arbeit von BURGDORF, Reichskonstitution und Nation.

144 Diese Kontroverse ist bisher noch nicht im Zusammenhang aufgearbeitet worden; einzelne Hinweise sind u. a. zu finden bei Richard SCHMIDT, Die Vorgeschichte der geschriebe- 
angerissenen und keineswegs vollständig angeführten) Themen und Fragestellungen ist auch für die Diskussion um die Bedeutung der englischen Verfassung von zentraler Bedeutung gewesen.

Ein weiterer Aspekt, vor dessen Hintergrund eben jene Diskussion gesehen werden muß, ist die Herausbildung von Stereotypen bestimmter Nationalcharaktere im frühneuzeitlichen Europa und den damit verbundenen Vorurteilen: Auch alle vermeintlichen Vorbilder sind von den Gegenbildern und den Feindbildern nicht zu trennen. Mit Recht ist darauf hingewiesen worden, daß „das frühmoderne nationale Vorurteil als Teil eines nationalen Geschichtsbildes zu einem konstitutiven Bestandteil der jeweils eigenen nationalen Kultur" geworden ist, denn „das Vorurteil gehört gleichsam zu den Konstitutionsbedingungen der Bildung von Nationalstaaten: ohne Vorurteil und nationale Mythisierung - so könnte man überspitzt formulieren - keine Staats- und Nationsbildung"145. Man hat es hier mit einem gewissermaßen dialektisch sich vollziehenden Vorgang zu tun: Auf der einen Seite „die Herausbildung eines europäischen Systems von Wissensvermittlung, -ermittlung und -tradierung ..., das ohnegleichen ist“ - und hierzu gehört auch das intensive Interesse an den jeweils anderen politischen Systemen und Verfassungsordnungen -, auf der anderen Seite aber wiederum „eine sprachlich-national orientierte Wahrnehmung des Fremden, die vor allem erklärlich ist aus der Abgrenzung, die für die eigene

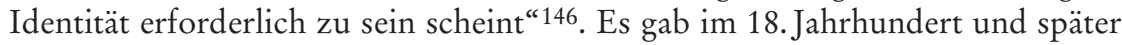

nen Verfassungen, in: RichaRd SCHMidT / ERWIN JACOBI, Zwei öffentlich-rechtliche Abhandlungen als Festgabe für Otto Mayer, Leipzig 1916, S. 79-191; NiKLAS LuHMANN, Verfassung als evolutionäre Errungenschaft, in: Rechtshistorisches Journal 9 (1990), S.176-220; DERS., Das Recht der Gesellschaft, Frankfurt a. M. 1993, S.470ff.; DieTER GRIMM, Verfassung, in: DERS., Die Zukunft der Verfassung, Frankfurt a. M. 1991, S. 11-28; DERS., Entstehungs- und Wirkungsbedingungen des modernen Konstitutionalismus, in: ebd., S.31-66; mit Blick auf den modernen Konstitutionalismus: Hasso Hofmann, Zur Idee des Staatsgrundgesetzes, in: DERS., Recht - Politik - Verfassung. Studien zur Geschichte der politischen Philosophie, Frankfurt a. M. 1986, S. 261-295, und KLAus STERN, Die Verbindung von Verfassungsidee und Grundrechtsidee zur modernen Verfassung, in: Staatsorganisation und Staatsfunktionen im Wandel, hrsg. v. GEORG MÜlLER / RENÉ A. RHINOW / GERHARD SCHMid / LuZIUS WildHABER, Basel u. a. 1982, S. 197-207.

145 Winfried Schulze, Die Entstehung des Vorurteils. Zur Kultur der Wahrnehmung fremder Nationen in der europäischen frühen Neuzeit, in: Europa und der Norden. Bericht über das 7. deutsch-norwegische Historikertreffen, Oslo 1995, S.7-39, hier S.10; über England als Gegenstand dieses Vorurteils siehe auch die Bemerkungen S.25ff.; zum Zusammenhang des Themas vgl. aus der älteren Literatur auch die sorgfältige Analyse von ERNEST BARKER, National Character and the Factors in its Formation, 4. Aufl., London 1948; außerdem Michael MAURER, „Nationalcharakter“ in der frühen Neuzeit, in: ReINhard Blomert / Helmut Kuzmics / AnnetTe Treibel (Hrsg.), Transformationen des Wir-Gefühls. Studien zum nationalen Habitus, Frankfurt a. Main 1993, S.45-81; DERS., Nationalcharakter und Nationalbewußtsein, passim.

146 So die treffende Beobachtung von SCHULzE, Die Entstehung des Vorurteils, S. 32; es heißt weiter: „Die eigene Identität wird sprachlich-historisch konstituiert und ist qua definitione um Abgrenzung und historische Erhöhung gegenüber dem Nachbarvolk bemüht“ (ebd.). 
keineswegs nur das Schlagwort von der „englischen Freiheit“, sondern ebenfalls auch dasjenige von der britischen Hinterlist, vom „perfiden Albion“147.

Schließlich ist auch die (vor allem nach Ende des Zweiten Weltkriegs) intensiv geführte Diskussion um deutsche und andere nationale „Sonderwege“ oder „Eigenwege“ als weiterer Aspekt für eine umfassende Fragestellung des Themas dieser Untersuchung mit in den Blick zu nehmen. Bedeutendster Stichwortgeber der These vom „deutschen Sonderweg“ war bekanntlich Helmuth Plessner, der bereits in seinem 1935 veröffentlichten Buch „Das Schicksal deutschen Geistes im Ausgang seiner bürgerlichen Epoche“ ausgeführt hatte, „die für Deutschlands Entwicklung so fragwürdige Obrigkeitsfrömmigkeit des Einzelnen und Staatsfrömmigkeit des Ganzen“ sei zum einen „in der politischen Indifferenz des Luthertums“, zum anderen aber in einer seit dem 17. Jahrhundert sich vollziehenden „Entfremdung“ Deutschlands von „dem Westen“ zu suchen ${ }^{148}$. „Deutschlands Gegensatz zum Westen“, sein „Protest gegen den politischen Humanismus Westeuropas“ habe dazu geführt, „daß die politische Ideenentwicklung in Deutschland kein Verhältnis zu den Leitbegriffen des Natur- und Völkerrechts und der aufgeklärten Humanitätsbewegung finden konnte“149.

147 Vgl. ebd., S. 26, sowie vor allem H. D. Schmidt, The Idea and Slogan of „Perfidious Albion", in: Journal of the History of Ideas 14 (1953), S. 604-616.

148 Helmuth Plessner, Das Schicksal deutschen Geistes am Ausgang seiner bürgerlichen Epoche, Zürich 1935, S.28. Neuausgaben dieses Buches erschienen 1959 und 1969 unter dem Titel: „Die verspätete Nation“.

149 Plessner, Das Schicksal deutschen Geistes, S. 41f. - Mit zunehmendem zeitlichem Abstand von der "Zäsur 1945“ wurde dieser Interpretation der deutschen Geschichte allerdings immer deutlicher widersprochen. Bereits 1978 wies Rudolf Vierhaus mit Nachdruck darauf hin, es sei an der Zeit, „die Unterschiedlichkeit von historischen Entwicklungen, vor allem von Modernisierungsprozessen, neu zu beleuchten und bisherige Deutungen kritisch zu überprüfen. ,Den' - sozusagen ,normalen' - Weg der Modernisierung, den alle Völker und Staaten gehen müßten, wenn sie nicht scheitern wollen, gibt es nicht, selbst wenn das Ergebnis dasselbe sein sollte", RUdOlF VierHaus, Die Ideologie eines eigenen deutschen Weges der politischen und sozialen Entwicklung, in: RUdOLF VON THADDEN (Hrsg.), Die Krise des Liberalismus zwischen den Weltkriegen, Göttingen 1978, S. 96-114, hier S.98; ähnlich auch Diethelm Klippel, Politische Theorien im Deutschland des 18. Jahrhunderts, in: Aufklärung 2/2 (1987), S. 57-88, hier S. 84ff.; aus der Perspektive des Frühneuzeithistorikers: HeINZ Schilling, Wider den Mythos vom Sonderweg. Die Bedingungen des deutschen Weges in die Neuzeit, in: Reich, Regionen und Europa in Mittelalter und Neuzeit, hrsg. v. PAULJoachim Heinig / Sigrid Jahns / Hans-Joachim Schmidt / Rainer Christoph SCHWINGES / SABINE WeFERS, Berlin 2000, S. 699-714. - Noch sehr viel schärfer hat Panajotis Kondylis 1986 die „Sonderwegsthese“ deutscher Autoren als „eine Übernahme und Theoretisierung der von den Siegern beider Weltkriege in polemisch-ideologischer Absicht konstruierten und propagierten Auffassungen über Charakter und Verlauf deutscher Geschichte“ kritisiert, PANAJOTIS KondYLIs, Konservativismus. Geschichtlicher Gehalt und Untergang, Stuttgart 1986, S.425; vgl. insgesamt die Ausführungen auf S. 423-428. - Daß die „Sonderwegsthese" in mancher Hinsicht nur die Umkehrung einer seit dem ausgehenden 19.Jahrhundert in Deutschland virulenten, durch den Ersten Weltkrieg nachhaltig beförderten, antiwestlichen Ideologie eines eigenen „deutschen Weges" gewesen ist, belegt die umfassende Arbeit von Bernd FaulenbaCh, Ideologie des deutschen Weges. Die deutsche Geschichte in der Historiographie zwischen Kaiserreich und Nationalsozialismus, München 1980. 
Auch von einem englischen "Sonderweg“ ist immer wieder die Rede gewesen ${ }^{150}$; sei es - eher indirekt - in der Tradition der „Whig interpretation of English history“, von der die neuere englische Geschichte als kontinuierlich sich entwickelndes Freiheitsgeschehen gedeutet wurde, - sei es aber auch im Hinblick auf gewisse, in der Sache nicht zu bestreitende Besonderheiten der englischen Rechts- und Verfassungsentwicklung ${ }^{151}$, die man etwa in der Sonderform einer geteilten Souveränität, in einer traditionalistischen, die britische Entwicklung „verspätenden“ Adelsdominanz, oder gar in der eineinhalb Jahrhunderte währenden unangefochtenen Herrschaft einer im Kern korrupten Oligarchie gesehen hat ${ }^{152}$. Bezeichnenderweise ist die These vom „modernfreiheitlichen“, bürgerlichen England, auf dessen Folie die Auffassung vom „rückständigen“ deutschen Sonderweg so gut gedeihen konnte, gerade von

150 Vgl. dazu u. a. HANS-Christoph SCHRÖDER, Die neuere englische Geschichte im Lichte einiger Modernisierungstheoreme, in: Studien zum Beginn der modernen Welt, hrsg. v. ReinHart Koselleck, Stuttgart 1977, S. 30-65; EIKe Wolgast, Absolutismus in England, in: Aspekte des europäischen Absolutismus, hrsg. v. HANS PATZE, Hildesheim 1979, S.1-22; GotTFried NiedHarT, Strukturwandel, Reformfähigkeit und Friedenswahrung: Probleme der englischen Geschichte im 19. und 20. Jahrhundert, in: Einführung in die englische Geschichte, hrsg. v. GotTFried NiedharT, München 1982, S.155ff.; Bernd WeIsBROD, Der englische "Sonderweg“ in der neueren Geschichte, in: Geschichte und Gesellschaft 16 (1990), S.233-252; Hermann Wellenreuther, England und Europa. Überlegungen zum Problem des englischen Sonderwegs in der europäischen Geschichte, in: Liberalitas, hrsg. v. NORBERT FinzSCH / HermanN Wellenreuther, Stuttgart 1992, S. 89-123.

151 So hat etwa BARKer, National Character, S.125f. die These vertreten, die Einzigartigkeit des englischen Nationalcharakters liege nicht etwa in der Begründung des modernen Parlamentarismus, sondern in der Entwicklung des Common Law: „... it may even be said that the Common Law has exercised a deeper influence on the behaviour and temper of the nation than any other single force“. - Percy Ernst Schramm wiederum hat die einzigartige Kontinuität der englischen Verfassungsentwicklung seit dem Mittelalter bewundernd hervorgehoben; vgl. PERCY ERnst SCHRAmM, Geschichte des englischen Königtums im Lichte der Krönung (1937), Darmstadt 1970, S.105: „Kaum sind noch Völker zu finden, denen es gelungen ist, ihren mittelalterlichen Staatsbau bis zum heutigen Tage immer wieder so abzuändern, daß er niemals ganz umstürzte und ganz von neuem aufgeführt werden mußte. Vielmehr gehört es geradezu zu den Kennzeichen unserer Zeit, daß Völker im Gefühle frisch geweckter Kraft sich eine ganz neue, die Vergangenheit bewußt überwindende Staatsform schaffen. Inmitten dieser Welt des Versinkens und Aufsteigens stehen als Zeugen der Vergangenheit und zugleich als Symbol des Heute nur noch aufrecht die Cathedra Sancti Petri in Rom und St. Edward's Chair in Westminster".

152 Vgl. - aus allerdings äußerst unterschiedlichen Perspektiven - etwa die Deutungen und Bemerkungen bei LeO Kofler, Zur Geschichte der bürgerlichen Gesellschaft. Versuch einer ,verstehenden“ Darstellung der Neuzeit nach dem historischen Materialismus, Halle a. S. 1948, S. 293-395; QUARITSCH, Staat und Souveränität, Bd.I, S. 424-471; KONDYLIS, Konservativismus, S.181-206. - Zur Frühgeschichte des britischen Verständnisses von Souveränität siehe auch UlRIKe KraUTHEIM, Die Souveränitätskonzeption in den englischen Verfassungskonflikten des 17. Jahrhunderts. Eine Studie zur Rezeption der Lehre Bodins in England von der Regierungszeit Elisabeths I. bis zur Restauration der Stuartherrschaft unter Karl II., Frankfurt a. M. u. a. 1977. 
angelsächsischen Historikern schon vor längerem sehr deutlich zurückgewiesen worden ${ }^{153}$.

In diesem Zusammenhang stellt sich also in Bezug auf den dritten Teil dieser Untersuchung die Frage: Lassen sich aus der ungewöhnlich intensiven deutschen Rezeption des englischen Verfassungsbildes tatsächlich Anhaltspunkte für eine Bestätigung der einflußreichen Plessnerschen These gewinnen, Deutschland habe sich vom naturrechtlichen politischen „Humanismus“ Westeuropas bereits seit der Reformationszeit abgewandt und auf einen „Sonderweg“ begeben, oder wird man, im Gegenteil, davon ausgehen können, daß auch die Deutschen Anteil genommen haben an der Entwicklung jener (von Ernest Barker so genannten) europäischen politischen „Wertordnung“, deren Kern in dem steten Bemühen um eine Form des Gemeinwesens besteht, das den menschlichen Grundbedürfnissen nach Ordnung, Sicherheit und Recht auf der einen, persönlichen und politischen Freiheiten auf der anderen Seite in gleicher Weise Rechnung trägt? Kann man also - wenn überhaupt - allenfalls von einem seit dem späten 19. Jahrhundert bestehenden deutschen „Eigenweg“ sprechen, der schließlich 1933 in den eigentlichen (nämlich den Hitlerschen) „Sonderweg“ einmünden sollte? ${ }^{154}$

Die auf den ersten Blick sehr spezielle Thematik der vorliegenden Studie über die englische Verfassung im politischen Denken des Ancien Régime fügt sich also in den Rahmen einer sehr breiten Fragestellung ein, die in ihren Details von bestimmten Besonderheiten der neueren Ideen- und Verfassungsgeschichte bis hin zu Grundfragen des historischen Verhältnisses der europäischen Staaten zueinander reicht. Man ist sich heute darüber einig, nicht mehr nur die Unterschiede, aber auch nicht mehr nur die Gemeinsamkeiten der europäischen Nationen zu berücksichtigen und jeweils unter- oder überzubewerten, sondern die europäische Geschichte als ein Wechselspiel des Ganzen und seiner Teile $\mathrm{zu}$ verstehen ${ }^{155}$. Eine nationalgeschichtliche Themenstellung hat heute, wie treffend formuliert worden ist, zuerst bei der Frage anzusetzen, „was ist das Europäische an uns, was verbindet uns mit unseren Nachbarn, was trennt uns natürlich auch, was macht das Gemeinsame dieses Europas aus dem Blickwinkel unserer Nationalgeschichten aus? Es klingt vielleicht paradox, aber es ist möglich, eine deutsche Geschichte in europäischer Perspektive zu entwerfen"156. Als ein solcher Beitrag zur Vermittlung nationalgeschichtlicher und europäischer Perspektiven versteht sich auch die vorliegende Arbeit.

153 David Blackbourn / Geoff Eley, Mythen deutscher Geschichtsschreibung. Die gescheiterte bürgerliche Revolution von 1848, Frankfurt a. M. u. a. 1980.

154 So die überzeugende These von Klaus Hildebrand, Das vergangene Reich. Deutsche Außenpolitik von Bismarck bis Hitler 1871-1945, Stuttgart 1995, S. 894.

155 Vgl. hierzu etwa die Beiträge zu dem Band: Heinz DuchHARdT / Andreas Kunz (Hrsg.), „Europäische Geschichte“ als historiographisches Problem, Mainz 1997 (darin bes. Heinz DuchHardt, Was heißt und zu welchem Ende betreibt man - europäische Geschichte?, S. 191-202).

156 So HaGen SCHUlzE in einem Interview mit dem „Rheinischen Merkur“, Nr. 14, 4. 4. 1997, S. 6 (die Hervorhebung von mir, H.-C.K.). 